\title{
Governance Drivers and Barriers for Business Model Transformation in the Energy Sector
}

\author{
Mary Jean Bürer, Matthieu de Lapparent, Massimiliano Capezzali, and \\ Mauro Carpita
}

\section{Contents}

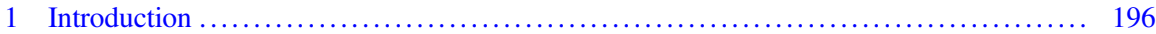

1.1 Barriers for New Energy Transition Business Models ...................... 200

1.2 Review of the Literature on the Energy Transition Progress .................. 201

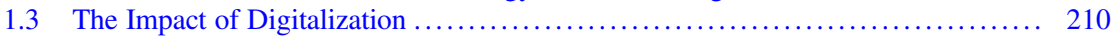

2 Exploring the Regulatory Framework for Business Model Change $\ldots \ldots \ldots \ldots \ldots \ldots \ldots \ldots .215$

2.1 The Context for Business Model Change for DSOs in Europe ................. 216

2.2 Policies Blocking Business Model Developments ......................... 218

2.3 Policies Promoting Business Model Developments ....................... 223

3 Insights from our Expert Workshop .................................... 226

3.1 Energy Transition Pre-Requisites Based on Time and Country/Region Context . . . 227

3.2 Changes Needed to Support Business Model Reconfiguration .................. 227

3.3 Changes Needed to Support Business Model Innovation ..................... 228

4 Additional Considerations for Good Governance of an Energy Transition .............. 230

4.1 The Contribution of the Finance Sector ............................... 230

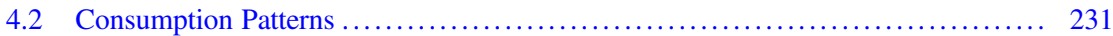

4.3 Building an Energy Transition Preparedness Index ...................... 233

5 Conclusions on Governing the Energy Transition via Business Model Change ......... 236

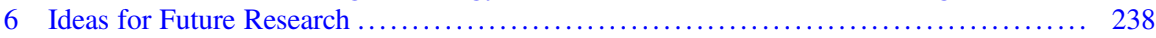

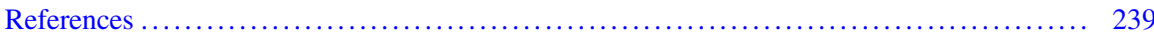

\begin{abstract}
Smart second-generation policies for energy transition governance have been less studied and reviewed in the literature. They are also difficult to compare or measure in terms of their effectiveness with regard to the energy transition, not only because each country's objectives and underlying drivers for an energy transition are different. Technological innovation and new technology deployment are only the tip of the iceberg. Understanding how to redesign energy governance to allow for business model reconfiguration among incumbents and how to stimulate business
\end{abstract}

M. J. Bürer $(\bowtie) \cdot$ M. de Lapparent · M. Capezzali · M. Carpita

Haute école d'ingénierie et de gestion du canton de Vaud, HES-SO, Yverdon-les-Bains,

Switzerland

e-mail: maryjean.burer@heig-vd.ch; matthieu.delapparent@heig-vd.ch;

massimiliano.capezzali@heig-vd.ch; mauro.carpita@heig-vd.ch 
model innovation by start-ups and new entrants is key for an effective and sustainable energy transition in the long term. However, beyond this, countries must address the underlying driving forces such as consumption patterns and the financial system. Therefore, business model transformation is not the only solution, but it is an important one and it requires well-designed policies. It also requires the involvement of all stakeholders at all levels of the economic fabric of each region and country. At the same time, we continue to measure progress on energy transitions in a superficial and extremely limited way. Policies must now be smarter, not just more ambitious in terms of appearances, and the measurement of energy transition progress must evolve as well. We discuss the full story of an energy transition to the extent possible in a single chapter. For example, we will review business models in different sub-sectors, policies that either block or promote such changes in each sub-sector chosen, and the elements that are necessary for energy transitions to become successful and sustainable without long-term government intervention and financial support. Finally, we also provide insights from an expert workshop held in 2019 and we outline our upcoming work on an Energy Transition Preparedness Index.

\section{Introduction}

There is no commonly accepted conceptual framework or unambiguous definition of energy transition and different timeframes and transition paths can be observed in different countries. It encompasses the political and increasingly social willingness to gradually phase out fossil energy resources in favor of low-emission sources, while putting in place measures for energy efficiency across all application sectors. However, besides these overarching objectives, there is no consensus on crucial aspects such as the time schedule of such a transition and its phasing, the role of state authorities, and the level of regulation. There is also no consensus on the very technologies that will indeed lead to the desired change. Addressing consumption patterns is also part of the solution but has not been a popular solution as countries continually seek economic growth and increasing purchasing power for their constituents. The place of natural gas and nuclear energy within the energy transition is vehemently disputed, within a broader discussion that also involves the need to decrease greenhouse gas (GHG) emissions, while satisfying expectations for continuous increases of purchasing power-a difficult nut to crack in any country.

A large number of studies have delved into the analysis of the conditions that could sustain the energy transition, covering a broad spectrum of possibilities from emerging technologies-e.g., in the field of energy storage or even new energy vectors such as hydrogen or methanol-to social behavior. ${ }^{1}$ As is the case with any major change, the energy transition will not happen if it does not involve all the

${ }^{1}$ Rieple et al. (2019). 
stakeholders at all levels of the economic fabric of each region and country. While certain measures can be sustained for a given period of time by state subsidies and policies - as has been the case in almost all industrialized countries with respect to renewable energy sources such as PV—, eventually the transition and its choices will gravitate towards clear market opportunities, those prospering without financial support mechanisms. Perhaps new, robust business models, ${ }^{2}$ combined with innovative regulations, tariff structures and market design, and reductions in consumption can lead to a true transition and sustain it over time.

Creative uses of technological innovations, innovative business models, and proactive corporate sustainability strategies can sustain the energy transition. These tools apply to the supply side but also to the demand side, addressing consumption as much as possible. Research conducted in the past has shown that the success of the energy transition relies more on other factors (social or businessrelated) and not just on technological innovation. ${ }^{3}$ The successful implementation of the energy turnaround thus requires business model innovation as one of the key drivers. ${ }^{4}$ In the energy sector, business model innovation has increasingly become a priority for the long-term profitability of utilities. ${ }^{5}$

Various recent scientific works have looked at the role of business model innovation in supporting fundamental value propositions and value creation changes to promote the energy transition. Loock used choice experiments with investment managers for renewable energy to identify which business models could succeed in the market. ${ }^{6}$ This work has provided some evidence that business models that focus on customers and that propose high-quality services are more attractive than business models oriented to low prices and state-of-the-art technologies. Richter explored existing business model approaches adopted by utilities with regard to renewable energy and found that utilities have developed viable business models for large-scale renewable energy generation but should invest further to take advantage of forthcoming business opportunities related to smaller distributed generation projects. $^{7}$

Still business model innovation alone will have limited power to change things without corresponding policies that increase the potential for change among incumbents and the impetus for change from start-ups and new entrants. There is a chickenand-egg problem where policies are needed to support decision-making on business model reconfiguration (among incumbents mostly); meanwhile, new business

\footnotetext{
${ }^{2}$ The most widely used definition is the one given by Osterwalder and Pigneur (2010), p. 14: "A business model describes the rationale of how an organization creates, delivers, and captures value". ${ }^{3}$ Boo et al. (2016).

${ }^{4}$ Boo et al. (2017).

${ }^{5}$ Castaneda et al. (2017) demonstrate the potential impact of renewable energy sources (RES) on electricity systems. The authors look in particular at how solar rooftop generation can be a threat to utilities.

${ }^{6}$ Loock (2012).

${ }^{7}$ Richter $(2012,2013)$.
} 
models are needed first to stimulate such policy developments. Often these new business models come from start-ups and new entrants, but they themselves struggle with the lack of clear policy frameworks because they often rely heavily on strategic partnerships with incumbent energy players to succeed.

The more important step to support the change process seems to be to create the right policy frameworks that support business model change.

In interviews that were conducted with utilities and other key energy sector corporate players throughout the last 5 years, executives agreed across the board that new business models are needed for the energy transition but that these new models will not gain momentum unless new policies and measures that support and partly guarantee their success are also implemented. This is especially true when we speak about business model reconfiguration (when a company changes its existing business model to a new one). The energy sector is very dependent on regulatory frameworks. Some authors have looked at the entire spectrum of regulatory frameworks for supporting renewable energy. ${ }^{8}$ Others have analyzed specific technologies that could enable the energy transition, like storage technologies. ${ }^{9}$ Finally, the fact that new business models will have to be backed by supporting regulatory frameworks has been confirmed by other research, such as by Facchinetti et al. ${ }^{10}$

In our continuing work on the energy transition, we aim at measuring the preparedness level of countries and key economic actors with respect to the energy transition. We assume that a successful energy transition will require both business model reconfiguration and business model innovation. Both incumbents (existing players like utilities) and new stakeholders such as innovative start-ups exploring new technologies and approaches are among the actors that will shape the transition. In this chapter, we review new business models coming from start-ups and new entrants as well as areas where business model reconfiguration is happening among incumbents.

Some work already exists to categorize business models by sub-sector. ${ }^{11}$ However, little work has tried to categorize business models by types of players. We will start this process by looking at business models that are most relevant to large incumbents on the one hand and business models that are more relevant to startups and new entrants on the other hand.

We then provide examples of policies or legislation that are either blocking business model developments or supporting such changes. The chapter is not able to provide a fully comprehensive view of all sub-sectors. Therefore, only a few

\footnotetext{
${ }^{8}$ Rubino et al. (2016).

${ }^{9}$ Broeckx et al. (2019).

${ }^{10}$ Facchinetti et al. identified favorable business conditions (that spurred investment in comprehensive business models) such as supportive policy scenarios, a growing economy, new development projects involving multiple energy carriers in areas characterized by a high building density, and target customers with a high willingness to pay (Facchinetti et al. 2016, p. 11).

${ }^{11}$ E. g. Burger and Luke (2016) review business models for Distributed Energy Resources (DER) and define business model archetypes for the three largest DER categories: demand response (DR) and energy management systems (EMS), electrical and thermal storage, and solar PV.
} 
sub-sectors are explored, with some focus on the power sector and innovative solutions in this sector allowing for decentralized energy systems, increased flexibility, and optimization of such systems, e.g., via different options for storage or "smart" energy management.

This chapter also reviews the existing literature to understand what drives business model transformation in the energy sector. We are assuming that an energy transition of a country or region (at least for the average OECD or European country) typically requires both: (1) business model reconfiguration among incumbents and (2) business model innovation among start-ups and new entrants. Both kinds of business model change require sustainability strategies combined with business model innovation that can vary from reactive to proactive strategies. Schaltegger et al. review such reactive to proactive sustainability strategies and identify sustainability strategies that must be combined with business model innovation. ${ }^{12}$ In order to better analyze business model changes in the context of the energy transition and understand what the antecedents for each kind of change are, we decided early in our research that it was important to obtain indicators for change related to two separate phenomena-business model reconfiguration and business model innovation. ${ }^{13} \mathrm{We}$ suppose that for an energy transition to happen rapidly and with economic success, we need policies and support mechanisms that stimulate and allow both kinds of business model change to occur and that enable synergies between the two. ${ }^{14}$

A good business environment for entrepreneurship and innovation of course supports business model innovation among start-ups and new entrants, but it also requires specific push factors relevant to the energy sector and the dynamics of each sub-sector where the business models apply. One of the key conditions is the right set of policies for a given country (regulations and new legislation), as well as on the regional level, and this is the focus of our work funded by the SCCER CREST, a consortium for socio-economic research on the energy transition in Switzerland.

Why is it important to look at this subject? We know a lot about technological innovation, but we know less about business model innovation. We are experimenting with it today-in real-time fashion. Many companies are even afraid of it, or at least very reluctant to engage in innovative market frameworks, especially

\footnotetext{
${ }^{12}$ Schaltegger et al. present three options for companies to combine strategic sustainability choices with business model innovation (Schaltegger et al. 2012, p. 110): "Defensive strategies with slight degrees of business model adjustment or adoption protect the current business model...; [a] ccommodative strategies go along with a change and some improvement of the business model, thus exerting some influence on business case drivers by experimenting within the current model...; [and] proactive strategies leading to (actual) business model redesign address many business case drivers strongly and continuously, with the effect of regular creations of business cases for sustainability."

${ }^{13}$ For definitions see Massa and Tucci (2014).

${ }^{14}$ For example, government support of start-ups with new business models can have a variety of effects: (i) incumbents can be encouraged to innovate and develop similar solutions, (ii) incentives can be created for incumbents to acquire innovative companies and internalize the innovation in their already existing business models, or (iii) innovation can inspire business model reconfiguration among incumbents.
} 
in countries with uncertain and evolving regulatory conditions. They are afraid of how it may impact their business, which until today has been very stable and lucrative because of regulations that supported the "historical" business model based on maximizing the number of $\mathrm{kWh}$ of power or cubic meters of natural gas sold to final customers, while decreasing both CAPEX (capital expenditure) and OPEX (operating expenses) as far as possible.

\subsection{Barriers for New Energy Transition Business Models}

The energy system must confront several barriers (market and social, financial, regulatory, and innovation barriers) that slow down implementation towards a more sustainable energy structure. These barriers are explained in a report by Boo et al. ${ }^{15}$ They explain that market and social barriers include the lack of knowledge, consumer engagement, and trust. The current system structure does not provide enough data to encourage consumers to change their behaviors. Innovative technologies such as smart meters and distributed generation can, however, enable customers to manage their own energy consumption. Another barrier is insufficient reference cases on new business models and approaches. Companies have a hard time to react when there are several new trends appearing at the same time and when uncertainty about the prospects of technologies or business models is high. Boo et al. also note that new business models face a difficulty in fitting the existing systems. There is a need for supporting infrastructures and technological changes. Internal management structures of large incumbent energy firms could add to the challenge. The implementation of new business models requires the collaboration of a number of different departments within a company that are likely to have different perspectives on change and to pursue their own objectives. There can be divisions between product and service developers or divisions between those who make investment decisions and those who supervise operations.

Financial barriers also hamper the transition. New financial models are therefore needed to meet investor needs and open up new pools of low-cost funds for energy projects. Other barriers mentioned in the literature are high upfront costs, especially for most energy efficiency measures that require more investment than conventional technologies. Decision-makers, including consumers such as private homeowners, might not be able or willing to make large upfront investments. In addition, it is difficult to access the necessary capital. A low return on investment is another barrier for new business models, especially for renewable technologies. Customers do not invest in renewable energy projects when the payback time is too long. Then, cumbersome regulation (and lack of clear legislation) is a clear barrier. The report by Boo et al. also describes restrictive rules that prevent companies from taking new approaches. In addition, permits for renewable energy installations are difficult to

${ }^{15}$ Boo et al. (2017). 
obtain. In particular wind energy project developers in Switzerland face a significant policy risk premium in the pre-construction stage that obstructs investments. ${ }^{16}$ Finally, there are innovation barriers, and with so many barriers to the innovation process, companies sometimes lose focus on market needs and the evolving needs of clients. Managements may have a historical bias and try to stick to the traditional business model for too long. ${ }^{17}$

\subsection{Review of the Literature on the Energy Transition Progress}

A recent report by the IEA on Energy Transition Indicators provides an overview of global energy investments and a comprehensive analysis that can be used for future work to develop an index showing the relative preparedness of countries for an energy transition. One point clearly made in this framework by the IEA is that one must look at data for the five underlying sectoral drivers (power generation, energy integration, industry, buildings, and transport) as well as both energy supply and energy demand indicators in order to assess the readiness of a country for an energy transition. ${ }^{18}$ Focusing mainly on one part of the energy system, for example only the oil and gas sector, would be insufficient and could be misleading.

Furthermore, before trying to learn from existing assessments of energy transition progress, it is important to note that we must distinguish between developed markets that have substantial infrastructure lock-in to overcome and emerging markets, especially Sub-Saharan Africa, where technology leapfrogging is a distinct possibility. ${ }^{19}$ Here we focus on the case of developed markets, those having infrastructure lock-in to overcome and entrenched business models supported by stable regulatory frameworks that have long existed. Indeed, energy transitions for countries where leapfrogging is possible require another focus and other policy frameworks. More research is needed in that area as well. In fact, an energy transition preparedness index is needed for such countries as well, but it is necessary to consider them separately. Mixing their energy transition analysis with that for developed countries could prove to be too challenging and lead to unsatisfactory results for all country types.

With regards to the energy transitions that most countries in developed markets are experiencing today, most work in the literature seems to focus on the transformation of markets in the short term. For example, Schleicher-Tappeser looks at how renewable energy will change the electricity markets in the next 5 years. ${ }^{20}$ The

\footnotetext{
${ }^{16}$ Ebers Broughel and Wüstenhagen (2021).

${ }^{17}$ Boo et al. (2017).

${ }^{18}$ IEA (2019a).

${ }^{19}$ This difference is also emphasized by Smil (2010).

${ }^{20}$ Schleicher-Tappeser (2012).
} 
author notes that increasing autonomy and flexibility of consumers challenge the top-down control logic of traditional power supply and push for a more decentralized and multi-layered system. The author explains that how rapidly and smoothly this transformation occurs depends largely on the adaptation speed of the regulatory framework and on the ability of market players to develop appropriate business models. Other pieces of work, such as Cross et al., have looked at progress in renewable energy and how this relates to targets in Europe. ${ }^{21}$ Finally, some pieces of work have focused on specific market niches or specific applications and the opportunities they offer for increasing flexibility. Such developments could either create momentum towards a different type of energy system or simply allow our existing systems to operate more efficiently. The flexibility that "aggregators" offer to the existing system is an example for this. ${ }^{22}$

On the macro-level, energy transition assessments (and indicators) are now available from various international institutions like the IEA, ${ }^{23}$ IRENA, ${ }^{24}$ and the World Economic Forum. ${ }^{25,26}$ Furthermore, other related indexes are valuable sources of energy- and policy-related indicators, such as the UN SDSN's SDG Index $^{27}$ and the 2019 SDG Index and Dashboards Report for European Cities. ${ }^{28}$ However, individual institutes around the world also develop their own pieces of work evaluating countries' progress on the energy transition. It is important to provide a deeper analysis of countries' progress and movements towards an energy transition, sometimes with a smaller set of countries, and not just global assessments that tend to overlook important details and over-use aggregated data. An example of a deeper analysis undertaken with fewer countries is the work of the German Forschungsstelle für Energiewirtschaft (FfE) for a project called eXtremOS. ${ }^{29}$ Researchers, of course, must accept a trade-off each time they start a project of

\footnotetext{
${ }^{21}$ Cross et al. (2015).

${ }^{22}$ An aggregator (also called a "virtual power plant") can create a sizable capacity similar to that of a conventional generator and it can operate many distributed renewable energy sources together. Aggregators can sell electricity or ancillary services in the wholesale market or in the system operator's ancillary services procurement. An aggregator contributes to the system's flexibility because it enables smoother integration of distributed energy resources into the power system (IRENA 2019a, p. 49).

${ }^{23}$ IEA (2019a).

${ }^{24}$ IRENA (2019a, b).

${ }^{25}$ The 2019 Energy Transition Index (ETI) "provides scores for 115 countries spanning the many dimensions of energy transition performance and enablers". The Index aggregates 40 energy transition indicators over these dimensions; this includes integrating information from data sources that describe country levels of energy pollution, prices, supply chains, infrastructure, political institutions, financial systems, human capital and more. "Country-specific scores are derived by normalizing the individual indicators and applying a weighting framework" (WEF 2019a, p. 9).

${ }^{26}$ Singh et al. (2019).

${ }^{27}$ Sachs et al. (2019).

${ }^{28}$ Lafortune et al. (2019).

${ }^{29}$ The main objective of this project was to investigate the value of flexibility related to European electricity market coupling (FFE 2020).
} 
this type, between comprehensive treatment of countries, markets, and technology options as opposed to the deeper understanding brought by a focus on fewer elements.

There are various energy transition assessments that have a special focus, such as policy or climate pledge assessments. When it comes to policy reviews, the Regulatory Indicators for Sustainable Energy (RISE) benchmarks national policies and regulatory frameworks on energy access, energy efficiency, and renewable energy. Other pieces of work come from the IEA, PBL, and the Climate Action Tracker. ${ }^{30}$

What we found, however, is that few studies assess the capacity of countries for business model innovation (especially not as related to the energy sector). This is of course difficult to do with existing available indicators and data, but we must develop new approaches to take into account qualitative aspects that are so important for energy transitions, such as the ability to support business model change. One realization as we attempted to develop our own index to measure countries' progress on the energy transition and their preparedness for an energy transition is that just because an aspect cannot be easily tracked by available data and measured, this does not mean it should not be part of an assessment. Otherwise, if this were the case, countries (and companies) might tend to focus only on areas where measurement is possible, even if investing in other avenues would finally be more transformative. This dilemma is already hurting the reputation of Environmental, Social and Governance (ESG) reporting and other corporate sustainability reporting schemes. ${ }^{31}$ The potentially negative influence of simplification (for communication purposes) on good decision-making does not only risk leading policy dialogues towards "quick fixes" that do not address the core problems of the system, but it also allows for an imbalanced importance of the media for consensus building and increases their power to influence the direction of political decisions, whether they are aware of it or not. The importance of the media and the need to manage governments' communications about their climate strategies ahead of time was demonstrated in Duygan et al. ${ }^{32}$ Adding the needed complexity to existing index projects around the world,

\footnotetext{
${ }^{30}$ The IEA Policy and Measures databases offer access to information on energy-related policies and measures taken or planned to reduce greenhouse gas emissions, improve energy efficiency, and support renewable energy development and deployment. The PBL Netherlands Environmental Assessment Agency provides the Climate Pledge Nationally Determined Contribution (NDC) tool, which projects country-level emissions to 2030, under the scenario of full implementation of Paris Agreement NDCs and under the trajectory of current national climate and energy policies. Finally, the Climate Action Tracker tracks the emission commitments and actions of countries and provides an assessment of individual national pledges, targets and NDCs as well as currently implemented policies to reduce their greenhouse gas emissions (WEF 2018).

${ }^{31}$ Over the last years, many papers (e.g., Pojasek and Toolbox 2010; Hedstrom 2019) have looked at the counter-productive impacts of reporting schemes used today to measure corporate sustainability. Also, ESG reporting is shown to be taken-up by companies more due to a herding phenomenon, which means that companies that report are not driven to report for value creation purposes (Przychodzen et al. 2016). One could learn from this experience and avoid developing energy transition reporting tools that do not create real value for stakeholders.

${ }^{32}$ Duygan et al. (2021).
} 
speaking about business model innovation as a key input for leadership, and not simply accepting an assessment just because it achieved consensus in a given industry setting is part of creating the appropriate dialogue needed for good policy-making around the energy transition.

\subsubsection{Oil and Gas}

According to the IEA's World Energy Investment Report of 2018, the oil and gas sector is changing for a number of reasons. The report states, for example, that there has been a broad shift in favor of projects with shorter construction times that limit capital at risk. In addition, the oil and gas sector is changing because people and investors are requesting it to change. The Oil and Gas Climate Initiative (OGCI), which brings together 13 of the world's top oil and gas companies, has pledged to reach its methane intensity target of $20 \%$ by 2025 , and energy companies are increasingly shifting towards producing gas. ${ }^{33}$ Power-to-X technology innovations also open up new opportunities for the oil and gas sector to integrate with the power sector and allow for business model change.

In the future, one could also imagine self-consumption communities or industrial parks working as microgrids and potentially producing excess energy that can be stored and traded. Hydrogen can store such excess electricity, for example. This would allow for revenue generation, even in the context of social housing projects if they operated on a renewable-based microgrid, using technologies to control and optimize demand and supply curves locally. ${ }^{34}$

The California Energy Commission (CEC) speaks about the experiences of several microgrid projects around the world. One of them is the ENGIE "Center of Excellence" microgrid in Singapore, where the most innovative aspect is probably the integration or use of hydrogen as an energy storage medium. ${ }^{35}$ The report explains that the system is targeting off-grid customers. ${ }^{36}$ Therefore, there are no opportunities for traditional revenue streams that are tied to the grid. However, the project proved the ability to use excess renewable energy to create hydrogen fuel for transportation. Of course, for any future microgrid project, stored hydrogen could be a potential revenue stream for other applications in the local, or regional, economy. Selling hydrogen for local ground or marine transportation could be one revenue stream. In terms of other areas of transition, energy efficiency has changed the game

\footnotetext{
${ }^{33}$ Bousso (2018).

${ }^{34}$ Cases and business models for microgrid projects, sometimes integrating the production of hydrogen or other products, have been studied by several research projects. One was conducted for the State of California in 2018 (CEC 2018), and more cases have emerged more recently around the world such as in Sweden (Ali 2019).

${ }^{35}$ Excess renewable energy generated from wind and solar is converted into hydrogen via electrolysis. Some of this hydrogen is diverted to motor vehicles, with the residual hydrogen combusted in a fuel cell.

${ }^{36} \mathrm{CEC}$ (2018).
} 
too. Prices for some efficient goods have continued to fall, and many energy efficient investments are already cost-effective with relatively short payback periods.

More innovative business model changes are also happening in this sector, and a transition from oil to gas is apparent in many countries around the world, having an important impact on carbon emissions; however, critics say the industry is not doing enough. ${ }^{37}$ Some examples of more innovative business models being explored at least by certain companies are: (in the mobility business) capturing value by switching to a services model as opposed to today's traditional model of selling fuel for transportation, for example, by charging customers per kilometer, irrespective of the type of energy supplied. ${ }^{38}$

Some companies are exploring the possibility of "independent retailers". Such companies will not necessarily be involved in production activities, but they might engage in new activities including commercializing fuels, LPG and/or electricity. ${ }^{39}$ Different business models will emerge. The authors of a recent report on the future of oil companies predict that many of the International Oil Companies (IOCs) will move in the direction of "energy holding" companies, while some large National Oil Companies (NOCs) may try to prolong their existence through scale advantages in the model of an "XXL oil company". 40 The report also notes that IOCs with limited access to fossil resources and high exposure to environmental topics and customer preferences will lead the "surpassing petroleum" trend. ${ }^{41}$

\footnotetext{
${ }^{37}$ Bousso (2018).

${ }^{38}$ Monzon et al. (2019), p. 68.

${ }^{39}$ They can also increasingly commercialize these fuels together with non-energy products and services. In fact, the value of an international brand for fuel retailing may be limited today (Monzon et al. 2019, p. 66). This is due to competitive barriers to capturing margins from new products and services at petrol stations that are largely owned by third parties. These factors represent major challenges for players that aspire to maintain their growth rates and levels of return on the capital employed. To remain competitive, a strong innovation capability is therefore needed in the sector to develop differentiated and viable customer-centric solutions.

${ }^{40}$ Monzon et al. (2019), p. 66.

${ }^{41}$ Monzon et al. (2019), p. 59.
} 
The Coronavirus and the Impacts of the Oil Shock of 2020 As we are writing this chapter in March 2020, the coronavirus is rampaging country by country, and many analysts are trying to understand what could be the implications of the virus on the global economy. One of the sectors that is already affected is the energy sector. At first the renewable energy sector was affected (China holds elevated weight in the industry's supply chain), but the oil and gas markets were affected via the impact on demand for transport fuels, too. This worsened due to uncoordinated supply management among the largest oil producing countries. Some fear that meeting energy transition goals will become even more challenging all around the world, and especially in continents like Africa, if oil prices remain low. On the other hand, it is difficult to predict what will happen. Lower oil prices also could lead countries to undertake fossil fuel subsidy reforms more easily. ${ }^{42}$ Nevertheless, after the coronavirus became a global pandemic in March 2020, some started to predict that the oil shock of 2020 would lead to further challenges with regard to meeting countries' energy transition goals. ${ }^{43}$

New business models for cleaner energy systems will help, but if oil is very cheap, even the best efforts to support business model innovation for clean energy sources will have a limited impact. The only way out of this problem is strict policies to support such business models for the energy transition, but this can hardly be expected in many developing countries, especially after a coronavirus pandemic and the various economic fallouts related to it. On the other hand, in certain countries some smaller markets may still boom. For example, today the off-grid solar market is booming around the world. 600 million people in Sub-Saharan Africa are currently without power. ${ }^{44}$ Lease models or what are called "pay-as-you-go" models for stand-alone systems and other new business models combined with such technologies will most likely still have a market in Africa. Energy efficiency and business models for energy savings may have less uptake, but they will be valid in all cases, no matter which fuels dominate markets in the future. However, issues like transportation will become increasingly difficult to address all around the world if fuel prices are too low. The key to transportation is indeed to reduce the need for transportation or lower consumption, but we have seen how

(continued)

\footnotetext{
${ }^{42}$ Merrill et al. explain that it became easier to reform fossil fuel subsidies in the past when oil prices were low (IISD 2017, p. 2).

${ }^{43}$ Montgomery (2020).

${ }^{44}$ Sioshansi (2018).
} 
countries have responded to low oil prices in terms of consumption patterns and choice of vehicle (e.g., the rise in SUV sales in the United States after the oil price collapse of 1986). ${ }^{45}$ As we are writing this, we also hope that COVID19 will not lead to a global economic downturn, resulting in job losses and potentially political and social unrest. We know that during economic downturns people can develop attitudes that help to fuel unrest, terrorism, or even war. $^{46}$ The energy transition will be more than a second priority under such scenarios.

\subsubsection{Power Generation and Flexibility Markets}

While there are many aspects that we cannot cover in one chapter, it is clear that in almost any energy transition the power sector integrates a high amount of renewable energy. In a report by IRENA, the importance of power system flexibility is highlighted. ${ }^{47}$ The Association for Renewable Energy \& Clean Technology (REA) evaluates a select number of countries regarding their flexibility services and other related transition factors. ${ }^{48}$ These are specifically transition factors regarding flexibility that can predict readiness for an energy transition at least for power generation in a given country. The transition factors considered by REA are market access, socio-political support, and technology potential. Regarding market access one aspect that REA attempts to measure is whether regulation enables fair access for all providers. With regard to socio-political support, REA looks at whether flexibility needs are recognized but also if there is a supportive political and public consensus and if public policy and regulation are aligned. Finally, regarding technology potential, REA takes into account if the country enables grid accessibility, EV infrastructure deployment, digitalization, and innovation.

According to REA, power systems must be able to operate in circumstances where renewable energy output may vary significantly from hour to hour. As generators are replaced by renewable energy generation with more volatile outputs,

\footnotetext{
${ }^{45}$ Gately (1986).

${ }^{46}$ Liu (2018).

${ }^{47}$ The report (IRENA 2018, p. 23) notes: "A power system can be considered flexible if it can costeffectively, reliably and across all time scales: (1) Meet the peak loads and peak net loads, avoiding loss of load. (2) Maintain the balance of supply and demand at all times, and ensure the availability of sufficient capability to ramp up and down, the availability of sufficient fast-starting capacity and the capability to operate during low net loads. (3) Have sufficient storage capacity ... to balance periods of high VRE generation and periods of high demand but low VRE generation. (4) Incorporate capabilities to adjust demand to respond to periods of supply shortages or over generation."

${ }^{48}$ REA (2019). REA is the Association for Renewable Energy and Clean Technology in the UK. It is a not-for-profit trade association established in 2001 and a coalition built to be the voice for renewable energy and clean technology in the UK, with 550 member organizations representing every type of renewable energy.
} 
new providers of flexibility services are emerging, including distributed generation, energy storage, and demand response. ${ }^{49}$ However, providers face barriers such as limitations to access flexible power markets.

\subsubsection{Coal}

To measure any energy transition progress, it is key to look at how coal-fired power generation is phasing out or continuing. The IEA tracks coal-fired power and reports on trends. ${ }^{50}$ It found that coal generation in Asia-particularly China and Indiaincreased significantly, but it fell elsewhere, including in the United States and Europe. Coal remains the largest source of electricity generation worldwide, with a share of $38 \%$.

The report notes that coal-fired power generation in the United States continued to drop in 2018 (by $60 \mathrm{TWh}$ ) despite strong electricity demand growth, as $15 \mathrm{GW}$ of coal capacity were retired. As for Europe, coal generation also decreased (by $20 \mathrm{TWh}$ ), mainly because of strong renewables-based expansion. Some countries have announced coal phase-outs: Germany, the largest coal consumer in Europe, plans to be coal-free by 2038. However, many believe this is too late. Despite the complexity of the situation, involving job losses in parts of the country, the German public approves of the way the government has decided to deal with the coal and nuclear phase-out. ${ }^{51}$

In this book chapter, we consider business model change opportunities and policies to support these changes for different sub-sectors. For coal, the best option is perhaps not to innovate the business model that makes coal investments work but to rather slowly phase out of coal; but every country will have its strategy on what to do and how to do this. In the future, geopolitical changes may even make coal investments more attractive for some countries. As for those that are phasing out of coal, there are different strategies for dealing with such phase-outs.

Historically, the traditional utility business model of selling electricity from largescale thermal power plants and expanding grids to meet rising demand has supported strong balance sheets. In many markets, utilities serve as reliable purchasers of power, and this facilitates investments by independent power producers. However, today, as we face other priorities including climate change, air pollution, and the energy transition, such investment decisions are becoming more complex. The business model is simply less attractive than in the past. However, regulatory frameworks can sometimes maintain business models which would otherwise

\footnotetext{
${ }^{49}$ REA (2019), p. 4.

${ }^{50}$ IEA (2019b).

${ }^{51} \mathrm{~A}$ look at the public approval of the energy transition law in Germany provides interesting insights. Referring to a study by the Potsdam Institute for Advanced Sustainability Studies (IASS), Wehrmann and Wettengel (2019) point out that "a surprising finding was that support for coal phase-out now enjoyed similar support as a nuclear phase-out, with approval by 63 percent of the population."
} 
phase out on their own for economic reasons. How the business models of utilities interact with policies and market designs (including those that are now finally changing) will have huge implications on a country's energy and climate change goals, especially when it comes to large-scale investment decisions like whether to invest in and build new coal-fired power plants or not.

Decades ago, Europe started with the unbundling of vertically integrated companies and the establishment of wholesale markets and retail competition. In recent years, the success of energy efficiency contributed to weaker electricity demand, policies supporting renewables prompted competition from independent power companies, and other challenges emerged. In short, these changes have weakened price signals for investment in traditional energy projects (from energy-only markets) and reduced the profitability of existing generation assets that are dependent on wholesale market revenues. $^{52}$

Today, innovations in the energy sector, such as virtual power plants allowing bilateral power exchange and increased roles for consumers and third parties to provide energy, capacity and flexibility services, facilitate new business models and allow for the reconfiguration of existing business models in the sector. New ways of trading energy are also emerging. For example, peer-to-peer $(\mathrm{P} 2 \mathrm{P})$ trading encourages more renewable energy distributed generation installations and increased local use of energy resources. However, the regulatory treatment-for example, regarding grid usage charges - must still evolve strongly before large-scale implementation of $\mathrm{P} 2 \mathrm{P}$ trading would be likely to provide any benefits to consumers. ${ }^{53}$ If $\mathrm{P} 2 \mathrm{P}$ trading of energy were allowed and self-consumption communities were further developed, increasingly one could imagine a scenario where central thermal power plants will be humanity's energy solution of the past. Such thermal generation will have completely new economics in the case of increased carbon pricing and once the power market and its mechanisms evolve over time. New technologies, such as battery storage even for on-grid storage, electric vehicles offering opportunities for distributed storage, and other electrification trends have the potential to change investment needs and approaches, thus opening up new opportunities but also creating a completely different system to work with. These factors raise a number of uncertainties for thermal power plants. However, today experiments with alternative systems are still not sufficient, and only a few countries ${ }^{54}$ are experimenting with the latest technologies such as $\mathrm{P} 2 \mathrm{P}$ trading for the time being.

\footnotetext{
${ }^{52}$ IEA (2017).

${ }^{53}$ IRENA (2019a), p. 49.

${ }^{54}$ For example, countries where P2P projects are in place include: Bangladesh (SOLShare), Germany (Lumenaza, sonnenCommunity), the Netherlands (Vandebron, Powerpeers), the UK (Piclo - Open Utility), and the United States (TransActive Grid) (IRENA 2019a, p. 49).
} 


\subsection{The Impact of Digitalization}

Digitalization is transforming every sector of the economy. Energy is no different. However, the way energy will be transformed by digitalization is likely to be more thought-through. The energy system requires reliable systems that have been well tested due to its high importance to all the sectors of any economy. In Bürer, de Lapparent, Pallotta et al., we elaborated on the risks that applying blockchain to the energy sector could impose on the electricity system and the caution needed as the reliability of service is so important for this sector. Meanwhile, there are many benefits to the energy transition if we increasingly take advantage of digitalization, for example with regard to energy efficiency. A range of challenging issues must be addressed if the world is to harness digitalization for greater energy efficiency.

\subsubsection{Business Model Change Due to Digitalization in the Power Sector}

Digitalization can convert data into value for the power sector. The application of digital monitoring and control technologies in the power generation and transmission domains has been an important trend for several decades. Switzerland aims to modernize its economy and society by embracing digitalization and plans to take a leading role in this domain. The Swiss digitalization action plan resonates with the Energy Strategy 2050, which supports (i) the optimization of the power system as opposed to only investing in traditional grid enforcement and (ii) the electrification and decentralization of the energy system through digitalization.

Wider usage of smart meters and sensors, the application of the Internet of Things and the use of large amounts of data with artificial intelligence have created opportunities to provide new services to the system. Digital technologies support the transformation of the power sector in several ways, including better monitoring of assets and their performance, operations that are more refined and control closer to real time, the implementation of new market designs, and the emergence of new business models. ${ }^{55}$

Several recent reports have put the grid in the center of the power system and discussed the issue of digitalization. Digital technologies can provide solutions for the energy transition because they can be used to (1) allow for better flexibility in energy systems, but also (2) to reduce energy intensity. For example, two reports from IRENA and the World Economic Forum (WEF) have recently underlined these aspects. IRENA indicates digitalization as a major driver for innovation and as a solution to energy sector challenges. ${ }^{56}$ Meanwhile, a WEF report ${ }^{57}$ calls for attention to the interconnectivity of the power system, in terms of both grid elements and

\footnotetext{
${ }^{55}$ IRENA (2019a), p. 31.

${ }^{56}$ IRENA (2019a).

${ }^{57}$ WEF (2019b).
} 
associated stakeholders. It also brings to light what impact a breach in the grid, physical or cyber, can have on an entire economy and society.

Digital technologies like those used for communications, smart meters, and IT systems are considered as enabling technologies for flexibility markets and therefore for the integration of renewables into the energy system. In a report by REA, experts were asked about various aspects supporting energy transition preparedness in nine European flexible power markets. The report comes to the following conclusion:

In high scoring countries, digital technologies i.e. communications, dispatch, smart meters, data standards, and IT systems across markets, are a key enabler for flexibility markets. In lower scoring markets not all this digital infrastructure is in place. ${ }^{58}$

The IEA believes digitalization will also impact energy intensity. IEA's "Energy Efficiency 2019" provides an overview of where every country stands and how well countries have done with regard to energy intensity. ${ }^{59}$ Beyond that, their emphasis on digitalization as an enabler is of special interest to us. There is a benefit from digitalization; however, it must be said that there can also be a cost to digitalization in that digital technologies also consume energy. The report looks at various reasons for the recent deceleration in energy efficiency progress, including the increasing use of digital technologies around the world. However, the authors mostly focus on ways in which digitalization is transforming energy efficiency and increasing its value. The report explains that, through multiplying the interconnections between systems, digitalization enables benefits from such interconnections (among buildings, appliances, equipment and transport systems) to be tracked and efficiency gains to be measured and valued more quickly and accurately than before.

Finally, the IEA has identified a set of critical policy considerations within its new Readiness for Digital Energy Efficiency policy framework. This policy framework is designed to ensure that the benefits of digital energy efficiency are realized through policies that address a range of issues. These range from balancing data accessibility with data privacy to helping remove regulatory barriers to innovation. The framework also mentions policies to "encourage technology and business model innovation". 60

Advancements in the decentralization of energy systems and electrification have made digitalization more relevant over the last years. The many new assets (such as many small generators on the supply side and many new loads from the electrification of heat and transport on the demand side) have an impact on the power system and make management and control very important for the energy transition and its success. Digitalization can therefore enable the management of large amounts of data and optimize systems with many small generation units. ${ }^{61}$

\footnotetext{
${ }^{58}$ REA (2019), p. 5.

${ }^{59}$ IEA $(2019 \mathrm{c})$.

${ }^{60}$ IEA (2019c).

${ }^{61}$ IRENA (2019c), p. 16.
} 
According to the report by IRENA, digitalization allows for enhanced communication, control and eventually automated smart contracts based on blockchain technology $^{62}$ that will allow distributed energy resources to be bundled by "aggregators". 63 The authors say that digitalization will also enable enhanced controllability - if assets could be controlled remotely and used for demand response-, behind-the-meter generation, home energy management, and electric vehicles (EVs). Finally, the authors believe that digitalization can increase flexibility and enhance the ability to accommodate the intermittency of renewables. The report also explains that digital technologies unlock the flexibility from different sources. For example, the cost of grid integration can be cut by better managing various devices such as EVs, battery management systems, demand response, and other devices that intelligently control solar generation for daytime loads and storage for night-time uses. ${ }^{64}$

The Internet of Things (IoT) also allows for data hub developments to support electricity retail markets and other innovations. ${ }^{65}$ The IoT enables real-time communication through the Internet, across the grid, and facilitates information gathering and exchange. It also facilitates exchange of information among devices in electricity demand centers (such as homes or commercial and industry facilities). According to IRENA, the IoT, together with optimization algorithms, could increase system flexibility by enabling remotely managed and/or rapid automatic changes in distributed resources and demand. ${ }^{66}$ IoT can also allow for improved renewable energy forecasting and trading and decreasing uncertainty. ${ }^{67}$

In this area of digitalization and with regards to new business models, it is possible that the combination of new technologies (like blockchain) and new policies such as those that allow the trading of energy savings can lead to new business model opportunities.

Otherwise, in terms of trading energy, digital solutions, such as those based on blockchain, can also be applied. Currently, the most uncertain application for energy is peer-to-peer energy trading. However, business models that enable distributed energy resources to provide services to the grid are much stronger so far. ${ }^{68}$ As for

\footnotetext{
${ }^{62}$ Blockchain is a distributed ledger technology that can be used to securely record all transactions taking place on a given network. Blockchain potentially allows: (1) increased direct trading and sharing of verifiable information, removing the need for the middleman and enabling newer / lowercost operating models on a smaller scale; (2) flexibility in the system, enabling decentralized flexible energy sources to provide services to the electricity grid; (3) new markets and transactions with products with a certified and trustable energy footprint; and (4) potential cyber security benefits, IRENA (2019a), p. 46.

${ }^{63}$ IRENA (2019c), p. 16.

${ }^{64}$ IRENA (2019a), p. 45.

${ }^{65}$ NordREG (2018).

${ }^{66}$ IRENA (2019a), p. 45.

${ }^{67}$ IRENA (2019a), p. 45.

${ }^{68}$ Bürer et al. (2019) look at different use cases for blockchain in the energy sector and provide insights on the key risks and opportunities for blockchain in light of the energy transition.
} 
peer-to-peer energy trading, blockchain technology allows transactions to be facilitated differently. Today they are facilitated by third parties, suppliers and system operators, whose main tasks are centrally compiling information on loads and generation or contracting supply and distribution services. Blockchain technology enables new ways of organizing decentralized persons without the immediate need for one centrally connecting entity, as explained in Diestelmeier. ${ }^{69}$ However, this implies profound legal and policy consequences. Meanwhile, more research is needed and a better understanding is required regarding the potential of blockchain to enable a very different management system for electrical energy. ${ }^{70}$ Diestelmeier identifies those main policy implications for EU electricity law and thereby adds to the discussion on how blockchain technology could facilitate "prosumers" to develop as independent market participants in the electricity sector from an energy law perspective. ${ }^{71}$

Finally, digitalization leading to more streaming, data centers, data networks, and other uses such as bitcoin also brings questions about increasing energy consumption from digitalization, and it must be managed properly in order for a country to be a leader in the energy transition. ${ }^{72}$

Digitalization offers some hope to companies that struggle (or will struggle) with the economic threats that come from potentially too rapid scenarios for the energy transition. This is explained in a WEF White Paper that provides examples of sectors and specific firms that suffered major losses after disruptions (e.g., GE that lost two-thirds of its capitalization in 2018 after it had to take a major write-down of its turbines division). ${ }^{73}$ Digitalization has provided hope to such firms in some cases: "[R]ecent history has also shown that many incumbents, especially in the electricity sector, have been able to change business models and investment strategies to take advantage of new opportunities centered more around energy services to customer, renewables and the digitalization of energy.",74

\subsubsection{Business Model Change Due to Digitalization in the Mobility Sector}

In Europe, data is available on electric vehicle charging points, ${ }^{75}$ electrified rail lines, ${ }^{76}$ private expenditure in R\&D in transport, ${ }^{77}$ the share of renewable energy in

\footnotetext{
${ }^{69}$ Diestelmeier (2019), p. 189.

${ }^{70}$ Bürer et al. (2019).

${ }^{71}$ Diestelmeier (2019), p. 194.

${ }^{72}$ Nouyrigat (2019).

${ }^{73}$ WEF (2019c).

${ }^{74}$ WEF (2019c), p. 24.

${ }^{75}$ The Netherlands being the leader in this area, followed closely by Denmark.

${ }^{76}$ Luxembourg, Belgium, the Netherlands, Sweden and Austria being leaders.

${ }^{77}$ Germany being a clear leader here.
} 
transport fuel consumption and the market share of electric passenger cars ${ }^{78}$ and more. You can easily evaluate countries based on many indicators for which data is currently collected. ${ }^{79}$ However, the mobility sector is quickly changing, pushed by new technologies, including digital technologies, new business models and a young generation that does not necessarily see the value in owning a car. Meanwhile, it is more difficult to measure and track business model innovation by country for this sector. One could track the uptake of digital technologies for the transportation sector, but it is more difficult to track new business models.

Navigant has put out a white paper that explains the concept of "value stacking" where business models are combined for innovative mobility concepts. ${ }^{80}$ In this report, different business model options are reviewed from "infrastructure developer", "charging service provider" and "load orchestrator" to "mobility provider". The report comes to the conclusion that in the near term, data sharing between policymakers, utilities, and fleet operators could help anticipate needs for charging infrastructure as mobility service fleets electrify. ${ }^{81}$ In terms of new business models facilitated by digital technologies or smart-grid control systems, several options and related business models are being conceived to support vehicle-to-grid (V2G) concepts, where EVs are integrated intelligently into microgrids and sometimes even used for distributed storage. ${ }^{82}$

Finally, a recent report by the European Joint Research Center (JRC) looks at the role of Distribution System Operators (DSOs) in Europe in the development of smart grid solutions. ${ }^{83}$ This study looks at the charging stations implemented by DSOs. As the report says, remarkably, the vast majority of the DSOs in the dataset are not owners of the charging points.

$10 \%$ of the DSOs with charging points in their territory have mentioned that they own a percentage of them. More than half of these DSOs operate less than the $9 \%$ of the charging points. It is expected that the number of charging points will increase in the close future with the expected increase of EVs. So far, the trend has been increasing. ${ }^{84}$

\footnotetext{
${ }^{78}$ Sweden being a clear leader in these two areas.

${ }^{79}$ European Commission (2019).

${ }^{80}$ Navigant (2019).

${ }^{81}$ This report and a report by the IEA (IEA 2019d) also speak about the intensive and distinct use patterns of shared and/or automated fleets. These use patterns imply higher (and different) needs for charging compared to private EVs. The availability and coverage of public and fast chargers could be a critical factor in how quickly these fleets become electric and how business models evolve around shared and/or automated mobility.

${ }^{82}$ It may also be worth mentioning that HEIG-VD is currently involved in a collaborative project with Planair, an energy consulting company. HEIG-VD has been charged to study and help industry stakeholders develop new business models in the context of V2G for a microgrid consisting of an innovation park where solar PV installations on the buildings provide power and EVs could provide distributed storage capacity to manage the microgrid.

${ }^{83}$ Prettico et al. (2019).

${ }^{84}$ Prettico et al. (2019), p. 56.
} 
The fact that the charging points are mostly owned by other entities shows that business model change is potentially driven by forces outside the DSOs' own innovation ecosystem. Policies to support new business models using digital technologies from start-ups and new entrants in the mobility sector could be an important policy strategy to pursue at this time, at least in the short term. In addition, policies and funding programs allowing for experimentation (sandboxes) for the application of digital technologies in the mobility sector, preferably programs matching incumbents with start-ups, could allow for further exploitation of potential gains from digital technologies in the mobility sector.

\section{Exploring the Regulatory Framework for Business Model Change}

Policy framework conditions to achieve business model reconfiguration-i.e., changes in the business models of Distribution System Operators (DSOs), Distribution Network Operators (DNOs), and Transmission System Operators (TSOs) - are going to be different from the policy framework conditions that support business model innovation by start-ups, spin-offs, and new entrants. The same is the case for incumbents of the transportation sector (automakers, oil and gas distributors, retailers of vehicles, and traditional firms in public transport) versus start-ups with new business models in this field (e.g., start-ups offering car sharing with or without electric vehicles and charging infrastructure, regional bus companies offering new mobility services).

Furthermore, it is a combination of policies that is needed and a well coordinated set of policies so that there are no extensive unintended impacts on other innovations. One of the ways to block business model reconfiguration or innovation beyond local or individual developments is via uncoordinated policy frameworks for individual sub-sectors, as is currently the case for biomethane because each country has different biogas regulations and agreements are missing. ${ }^{85}$ Meanwhile, each country must develop policies that match local needs and that correspond to the level of awareness of consumers.

The energy transition simply requires the participation of all stakeholders and this is why new approaches are needed to address this challenge, such as design thinking, co-creation, and systems thinking. This also means moving well beyond just carbon pricing, although carbon pricing has created important incentives to move away from fossil fuel energy sources and reduce consumption. In June 2019, 57 carbon pricing initiatives were implemented or scheduled for implementation. ${ }^{86}$ Such developments are helpful as indirect market-pull measures; however, more direct

\footnotetext{
${ }^{85}$ Mediavilla et al. (2013).

${ }^{86}$ This consists of 28 emission trading systems (ETS) in regional, national and subnational jurisdictions and 29 carbon taxes, primarily applied on a national level. In total, these carbon
} 
market-push and market-pull measures are needed now, especially those supporting business model innovation that has the potential to transform the industry while creating opportunities for growth.

We divide our discussion into examples of policies blocking business model developments and policies promoting business model developments for both actors (incumbents and start-ups or new entrants). Due to the limited space of this book chapter, we focus more on power generation and in particular on renewable energy. Therefore, an in-depth assessment including all sub-sectors cannot be provided. An overview of some business model innovation successes (and failures) in the transportation sector can be found in a paper by Wells. ${ }^{87}$ In this paper, we explore progress with regard to business model changes in the area of electric vehicle charging.

Finally, we will discuss the results from our workshop and conclude with findings relevant to our ongoing work - the development of an Energy Transition Preparedness Index (the first version of which will be launched in 2021).

\subsection{The Context for Business Model Change for DSOs in Europe}

According to the IEA, electricity sector investments have a strong relationship with government policies. Furthermore, according to the IEA, around three-quarters of utility earnings now stem from segments that offer more stable and predictable cash flows, such as networks and generation (e.g., renewables, co-generation, and some thermal power plants) that benefit from contracted or regulated pricing. ${ }^{88}$ European utilities are strategically re-orienting their businesses to adapt to the situation. Utility planning now emphasizes themes around business model transformation, enhanced operational efficiency, and improved financial management.

The European electricity industry association has also called for a new strategic vision for the sector. However, this ongoing change has not yet resulted in an earnings boost, according to the IEA. They explain that one reason is that business models for grids and renewables are capital-intensive, requiring continuous investment over time to expand revenues. ${ }^{89}$ Some EU member countries also have trouble meeting their renewable energy targets because support levels offered for renewable energy sources are too low and may be below long-term marginal costs. Also, there

\footnotetext{
pricing initiatives cover 11 gigatons of carbon dioxide equivalent $(\mathrm{GtCO} 2 \mathrm{e})$ or about $20 \%$ of global GHG emissions (CPLC 2020).

${ }^{87}$ Wells (2015).

${ }^{88}$ IEA (2017).

${ }^{89}$ IEA (2017).
} 
is sometimes insufficient electricity grid capacity to integrate renewable energy sources. ${ }^{90}$

Meanwhile, as for investment capabilities, European utilities are increasing their expenditures. In November 2017, six utilities collectively called on the European Union to support a strengthened renewable energy target of $35 \%$ by 2030 , compared with an originally proposed target of $27 \% .^{91}$ At the same time, the electricity sector has also witnessed rapid growth in new, less capital-intensive business models that leverage digital technologies to provide system and consumer services. ${ }^{92}$ However, current regulations do not necessarily provide the incentives for such investments and the value proposition for utilities, developers, and system operators is still not clear.

A report by the European Joint Research Center (JRC) also provides an overview of the situation of DSOs in Europe. ${ }^{93}$ The context for business model transformation in the energy sector is very complex and different in each country. Some DSOs have the capacity for lower transaction costs under certain new business model scenarios, while others will have clearly higher transaction costs for certain technological innovations and business model opportunities until the framework conditions change. Others can benefit from scale and from their scope (and importance) in the country, allowing for creativity to develop into new business opportunities. Some countries allow sandboxes for experimentation. Other DSOs can more easily utilize synergies with network investments. There is no one-size-fits-all solution to developing regulations (and legislation) for business model innovation, but experiences in one country can be used in another to allow for increasingly intelligent policymaking over time. Some policies will open up opportunities for new entrants to play a role in offering services to individual communities, and perhaps other countries will develop policies allowing for start-ups to bring in new technologies and business models where incumbents continue to maintain their connection to the customer.

\footnotetext{
${ }^{90}$ Ali et al. (2017).

${ }^{91}$ Reuters (2017).

${ }^{92}$ One model is the Virtual Power Plant (VPP) model that aggregates and trades small-scale energy resources on wholesale markets and provides coordinated balancing and ancillary services to grid operators. Asset-light business models of this kind can limit the network size to meet peak demand and have the potential to defer expensive future capital upgrades; see IEA (2017).

${ }^{93}$ See Prettico et al. (2019).
} 


\subsection{Policies Blocking Business Model Developments}

\subsubsection{For the Electric Power Sector}

The electric power sector includes many sub-sectors where important innovation is happening with regard to the energy transition and where policies can support, or block, innovations including business model innovation.

\section{The Case of Microgrids and Local Energy Ownership Models}

Many types of barriers exist for microgrids, from infrastructure to technical barriers, to public acceptance and environmental issues, to economic, market and financial barriers. But it is the regulatory and administrative barriers that remain the overarching issue for microgrids. Administrative issues can arise from the length, complexity and non-transparency of permitting procedures or from the lack of clear responsibilities and skills within the local and national authorities. In many countries, microgrids as energy distribution systems are still within a grey area in terms of regulation and legal status.

[T]here are no specific policies and regulations formulated for distributed generation (DG) and microgrid (MG) systems in the European Union. Each EU member state transposes the mentioned directives following the particularities of their national energy policies and regulatory frameworks for the promotion and development of renewable energies and microgrid systems. ${ }^{94}$

In Europe, managing a local distribution grid is a regulated activity. There are specific rules about who is allowed to deal with these configurations and in which cases. Completely islanded or grid-connected microgrids both represent a new development for energy regulators because they will entail updating the rules of the game. At the same time, regulators will need to completely reform the electricity tariff system that was established years ago for very centralized systems.

In a report by Gancheva et al. for the EC, lessons for local energy ownership models and an analysis of key barriers are also provided. The report explains that the first barrier relates to the legal standing of community energy, i.e., the constraints imposed by national legal frameworks that limit the conditions under which an energy community can be formed and operate. For example, securing access to the national electricity grid is vital for community energy projects. Examples showed that the costs, delays, and uncertainty associated with connection to the grid represent major barriers for groups developing community energy projects. Rules about the operation and connection of renewable energy sources and their systems in general affect the development of RE communities. As was shown in Germany, granting powers to local authorities by the national law helped the success of community energy in the federal states (Bundesländer). Therefore, the report

${ }^{94}$ Ali et al. (2017), p. 6. 
concludes that clear definitions and rules are needed while keeping some flexibility in order to allow the various models of local energy ownership to flourish. ${ }^{95}$

\section{The Case of Storage}

Regulatory support for storage can be expected to vary around the world, but many feel it is a game changer for renewables and should be supported by specific policy frameworks. In a report by STORY, a Horizon 2020 funded project, ${ }^{96}$ the authors explain that our energy system will have to tap into much-needed sources of flexibility if the EU's ambitious target of $32 \%$ renewables by 2030 is to be met. Energy storage will be a part of the mix to ensure the effective integration of intermittent renewable energy sources while maintaining grid stability. Energy storage can play a role in several areas: in the wholesale, the balancing, or the ancillary services market. However, for all areas, it is essential that barriers to entry be removed. The report explains that although market design changes may help to overcome certain obstacles, they are not enough to make the business case for energy storage viable. Similarly, appropriate tariffs are needed, but they are not sufficient by themselves. The report also explains that the EU has subsidized renewables, but it is not inclined to do the same for storage, where the EU seems to be banking on R\&D support programs. The hope is that innovation alone will help to further reduce the costs of storage technologies. Meanwhile, the United States did not wait for the costs of storage to drop. It has set targets for energy storage, granting subsidies to support those targets, similarly to its policy on renewables. Several states have already imposed energy storage deployment targets and in other states, target processes are underway. An order by the US Federal Energy Regulation Commission FERC (issued in February 2018) ${ }^{97}$ requires the creation of participation models for energy storage across the country in order to remove barriers to the participation of electric storage resources in the capacity, energy and ancillary services markets operated by regional transmission organizations and independent system operators. In specific states, different needs for storage have different regulatory implications. For example, in California, PG\&E's landmark energy storage solicitation where batteries were to replace fossil fuel generation on the power grid attracted attention in past years. ${ }^{98}$ It was the first time a utility and its regulators have sought to directly replace multiple

\footnotetext{
${ }^{95}$ Gancheva et al. (2018), p. 25.

${ }^{96}$ Broeckx et al. (2019), p. 18.

${ }^{97}$ Federal Energy Regulatory Commission (2018): Electric Storage Participation in Markets Operated by Regional Transmission Organizations and Independent System Operators, Order No. 841, 162 FERC $\ 61,127$, available at https://www.ferc.gov.

${ }^{98}$ Switching to batteries can lead to decreased reliance on gas. In the case of California, state regulators were already planning for three fossil fuel power plants to retire. They ordered PG\&E to seek alternatives to the generators.
} 
major power plants via battery storage. The request was approved by US federal regulators (FERC). ${ }^{99}$

In Switzerland there is also a legal framework supporting storage, but it is likely to evolve to facilitate the energy transition. Schreiber (2021) goes into more details about the current legal framework related to storage in Switzerland that exempts pump hydropower plants from paying grid fees but does not provide a clear framework for new storage technologies yet. He also explains the interesting role of private industry associations in the absence of a specific legislation on the other storage technologies. It is interesting to note that companies are driving the developments in this area probably because they see the potential for new business models related to other storage options in Switzerland. ${ }^{100}$ A good overview of the political frameworks in place today, the legislation that is being introduced, and other developments is provided by Global Legal Insights. ${ }^{101}$ Beyond federal legislation and regulation, since 1990, all cantons have drawn up their own energy legislation and regulations. In the Canton of Vaud, for example, one of the strategic axis areas in terms of infrastructure to support the energy vision of the Canton is to develop infrastructure for the storage of energy and to favor the convergence of grids. ${ }^{102} \mathrm{New}$ IT tools that are being developed and new management strategies and technologies will increasingly also allow the convergence of grids, including gas and power grids. Oversizing both networks is not the best solution when alternative approaches are apparent. ${ }^{103}$ As tools continue to be developed to help cantons, cities, and individual companies better manage their grids and the existing infrastructure, innovations in business models will emerge together with new technological options (storagerelated or other), and subsequently policy frameworks will be called to evolve in order to become better suited to energy transition strategies on the local, regional, and national levels.

Regarding the question whether Switzerland will follow or diverge from the EU on storage, the relationship between Swiss and EU legislation has to be analyzed. The recast Electricity Market Design Directive, part of the EU's Clean Energy for All legislative package, includes measures to adapt the EU electricity policy

\footnotetext{
${ }^{99}$ Bade (2018).

${ }^{100}$ The Swiss Federal Constitution (Bundesverfassung), the Energy Act (Energiegesetz), the $\mathrm{CO}_{2}$ Act $\left(\mathrm{CO}_{2}\right.$-Gesetz), the Nuclear Energy Act (Kernenergiegesetz) and the Electricity Supply Act (Stromversorgungsgesetz) are all integral parts of the instruments defining a sustainable and modern Swiss energy policy. In addition, energy policies at the cantonal level as well as the federal level are also based on the presentation of energy perspectives as well as on strategies, implementation programs, and the evaluation of measures at the municipal, cantonal and federal levels. Therefore, policies in Switzerland will evolve to facilitate the transition in each canton.

${ }^{101}$ GLI (2020).

${ }^{102}$ DIREN (2019).

${ }^{103}$ We developed a software tool under a project supported by the H2020 (the Horizon 2020 European funding program) called IntegrCiTy for the optimized development and management of gas and power grids, see: http://iese.heig-vd.ch/projets/integrcity. For this project, we worked with industry stakeholders to develop business model options for the software in a design thinking workshop held with local gas and power industry stakeholders in 2018.
} 
framework for the clean energy transition, including measures to enhance flexibility and enable consumer participation in energy markets. ${ }^{104}$ Furthermore, energy storage is also recognized as a distinct asset class in the directive, separate from generation. The measures are expected to facilitate energy storage investments. However, individual Member States still need to implement this directive into national law, and Switzerland will pursue this direction as well. The consulting company Norton Rose Fulbright has produced a report about the situation for storage, including an analysis of the regulatory environment. They mention that "the provisions of the directive entitling transmission system operators (TSOs) and distribution system operators (DSOs) to own and operate storage assets under certain circumstances may result in narrower or broader markets for storage services offered by independent storage operators in different Member States." Member States can now make strategic decisions to enable consumers to shift their demand, to allow self-consumption (like in Switzerland) and storage, and to enable dynamic time-ofuse tariffs as part of their implementation of this directive. The authors explain that the same is true for the role of aggregators and local energy communities addressed by the directive. Finally, the authors expect the rollout of smart meters to become increasingly important to enable the intended flexibility. ${ }^{105}$

Norton Rose Fulbright explore other examples of legal barriers for storage in their report. ${ }^{106}$ For example, the report explains the current situation in France, where, except for pumped storage, energy storage remains limited, but a forecast recently published by CRE, the French energy regulator, reports a potential for energy storage of between 1 and $4 \mathrm{GW}$ by 2030. The report covers several legal and commercial challenges for energy storage projects in France. Moreover, the French feed-in tariffs regime for electricity production favored the direct injection of electricity into the grid rather than its storage. Therefore, the report comes to the conclusion that multiple factors have hindered the emergence of an energy storage market in France.

\subsubsection{For the Heating and Cooling Sector}

In this section, we explore under which circumstances policies are blocking (or otherwise promoting) new business models and technologies in the heating and cooling sector, but also how sometimes other policies can cause unintended effects and reduce the incentives for such developments. According to a recent report on cities, two key elements are necessary for the sustainable energy transition to

\footnotetext{
${ }^{104}$ The directive aims to reduce the barriers to energy storage. It mandates fair rules in relation to network access and charging. It also mandates non-discriminatory and competitive procurement of balancing services. A wide definition of "energy storage" was chosen in the directive. That definition encompasses both reconversion to electricity and conversion into another energy carrier, like hydrogen gas; see NRF (2019).

${ }^{105} \mathrm{NRF}(2019)$.

${ }^{106} \mathrm{NRF}(2019)$.
} 
succeed: first a more rapid deployment of renewables in the sector and second widespread electrification in all economic sectors. The report explains that cities have a unique role to play in this mission. First, the heating and cooling sectors are local markets. Second, cities have an influence at a local level, and they can encourage their residents and other citizens to support the energy transition. For heating and cooling systems, the development of urban renewable heating and cooling markets is key to decarbonizing these sectors, the report explains. ${ }^{107}$

The Energy Performance of Buildings Directive (EPBD) of the EU ${ }^{108}$ outlines specific measures for the building sector, updating and amending many provisions from the 2010 EPBD. In Switzerland, many provisions exist to improve energy efficiency in buildings, but at present, approximately $50 \%$ of Switzerland's primary energy consumption is attributable to buildings: $30 \%$ for heating, air-conditioning and hot water, $14 \%$ for electricity and around $6 \%$ for construction and maintenance. ${ }^{109}$ New business models, e.g., combining business models for renewable energy with investment models for energy efficiency improvements, could incite investors to invest more in insulation, refurbishments, etc. New business models for buildings are also tracked in a report by Boo et al. ${ }^{110}$ and another review of business models for renewable energy in the built environment was conducted by Würtenberger and Bleyl. ${ }^{111}$ Indeed business innovation in the building sector is occurring all along the industry value chain, starting with the re-design of project delivery models and energy performance solutions and including deep renovation. Service-oriented business models are leading the way towards a greener building industry, in which there is considerable cross-sectoral collaboration. ${ }^{112}$

Affordable and reliable options to decarbonize the provision of heating and cooling in urban areas now include solar thermal, bio-heat and geothermal technologies. Renewables combined with energy efficiency improvements in cities have enabled the development of "net zero" buildings and districts. Solar thermal systems on building façades and rooftops as well as modern biomass stoves and boilers are also stand-alone solutions now available in many cities. ${ }^{113}$ A report prepared by the IEA about the German energy transition states that the government is still in the process of formulating a decarburization plan for the heating sector-which accounts for over $50 \%$ of final energy consumption. ${ }^{114}$

Nevertheless, in terms of energy efficiency, legal measures are starting to drive improvements in both Switzerland and Germany. In Germany, the Climate Action

${ }^{107}$ REN21 (2019b), p. 13.

${ }^{108}$ Directive 2010/31/EU of the European Parliament and of the Council of 19 May 2010 on the energy performance of buildings, Official Journal L153, 13-35.

${ }^{109}$ Swiss Federal Office of Energy (2019).

${ }^{110}$ Boo et al. (2017).

${ }^{111}$ Würtenberger and Bleyl (2012).

${ }^{112}$ Boo et al. (2017).

${ }^{113}$ REN21 (2019a), p. 22.

${ }^{114}$ IEA (2020). 
Programme 2030 contains important measures for the heating sector. ${ }^{115}$ However, policies and innovative measures that push for business model changes in the heating sector should be further explored in future research work. For example, there may be opportunities where new business models combined with innovative policy-making create incentives for energy efficiency improvements in existing buildings at the same time that investors invest in eco-villages or self-consumption communities, and this could be backed by specific policies and measures, locally or on the regional level.

\subsection{Policies Promoting Business Model Developments}

When we interviewed executives at the start of the SCCER CREST project, all executives across the board from technology providing firms to energy distribution companies to ICT firms in the energy business said that in order to have a successful energy transition, we need new business models, but in order to see these new business models emerge in the energy sector, we need new regulatory frameworks. ${ }^{116}$ Indeed, according to the IEA, across all power sector investments, more than $95 \%$ of investment is now based on regulation or contracts for remuneration. ${ }^{117}$ Investment in energy efficiency is particularly linked to government policy, often through energy performance standards. Likewise, it is clear and well-known that business models in the energy sector can only be successful if supported by regulatory frameworks and good legislation. Some examples of how policies support business model innovations are provided in this section.

\subsubsection{For the Transportation Sector}

Beyond the measures that are applied today (e.g., taxes for fuel, incentives for clean vehicles, and funding for public transportation), governments can also play a role in more directly creating business model change in the transportation sector in specific

\footnotetext{
${ }^{115}$ This includes measures such as tax relief for energy-efficient refurbishment of buildings. It also includes a premium for exchanging oil heaters for new, efficient heating systems. Finally, it includes the expansion of heat grids and district heating with a view to integrating renewable energy sources into heating networks (especially in densely populated areas). This strategy is also pursued in Switzerland in some regions. As for Germany, as the intended carbon tax will also apply to heating emissions, it is expected to bolster existing energy efficiency efforts in the sector (IEA 2020).

${ }^{116}$ Structured interviews were held with executives (or middle-managers) at ten major corporate entities in the energy sector, with interviews held from 2014 to 2016 and in different locations (Zurich, London, Lausanne, and on the phone with several other firms). For confidentiality, we have decided to withhold the names of the firms. They comprise firms in the energy technology business and the ICT business as well as utilities companies active in both distribution and production. We also interviewed two major auto manufacturers.

${ }^{117}$ IEA (2018a).
} 
areas. Governments can transform their transportation concepts and promote electrification. Such electrification is a new type of power demand for utilities and helps to drive innovation and decarbonization.

Governments, particularly municipalities, can provide their communities with access to greater transportation and fueling options through the T2G (Transportation-to-Grid) platform. However, today this is not a full reality yet in many cities. Most cities are still experimenting with such concepts and platforms. These efforts could support municipality goals such as addressing climate change. More simply, municipalities could provide more and more charging points for the public in cities, as is being done on a pilot basis today in Basel. ${ }^{118}$ Novel types of public-private partnerships with innovative financing schemes can be explored by cities, together with their local stakeholders. Another area for work to be done is defining new city planning rules to allow for both improved livability in a city and reduced emissions. Design thinking and co-creation workshops with urban dwellers could help develop solutions adapted to various specific sets of users. Comparing a city's status and accomplishments to general guidance and best practices for urban planners could be a starting point for deciding on where a city needs the most help and ideation inputs from inhabitants. Some guidelines are reviewed by Kodukula. ${ }^{119}$

In the transportation sector, standards for new vehicles sold or taxes to change the purchasing behavior of people with regard to vehicles help. However, they do not create special opportunities for business model developments or business model innovation. Policies in the transportation sector must start to become more strategic.

First, they must aim to decarbonize energy carriers and fuels, vehicles, and infrastructure. Second, incentives for such investments in infrastructure together with innovative local policies are needed. Furthermore, integrating public transport investments with private (passenger) transport business models needs to be further explored. If demonstrations prove these integrated concepts to be of interest to private investors, perhaps driven by prosumer-led business models intended for city inhabitants, then policies and specific programs could be developed to specifically promote such integration. For example, one idea is to use the DC network of public transport for the integration of Photovoltaics (PV) and as a charging point for electric vehicles $(\mathrm{EV})$. The aim of this integration is to stabilize the DC network of public transport and to offer new services and modes of supply. Such a configuration and its potential is studied in the framework of a project conducted at our school (HES-SO) called Projet InterHubEN. ${ }^{120}$ Third, policy frameworks can support strategic value chains and create conditions for new business models in terms of

\footnotetext{
${ }^{118}$ Some of these charging points are available in covered parking structures. Today just 10 parking places in the blue zone areas in the city are available with one hour more of parking than normally is the case in this blue parking zone and free unlimited parking during the night and the weekend. Each parking spot reserved for electric vehicles is equipped with a sensor so that users can use an application to know where public charging stations are available in the city.

${ }^{119}$ For cities that are revising their land-use plans or transport plans several recommendations such as linking land use and transport planning are made and summarized in Kodukula (2018).

${ }^{120} \mathrm{https} / / /$ heig-vd.ch/rad/groupes-transversaux/hub-mobilit\%C3\%A9/ra-d/projet-interhuben.
} 
supply chains. Policies can help reduce investment risks for the development of battery industry value chains, for example. Strengthened funding for battery manufacturing can be coupled with requirements regarding the sustainability of battery cell manufacturing and therefore improve the transparency of the raw material supply chains. ${ }^{121}$ Such innovations are on the level of sustainable innovative supply chain management, but they could also integrate new commercial business models. Finally, policies could also be developed to support utilities and energy providers that wish to redefine themselves. Utilities as electric distribution providers have the opportunity to enter the transportation business by delivering electricity to plug-in electric vehicles (PEVs) and extending their networks to support PEV charging infrastructure. Transportation electrification is an opportunity for utilities to proactively redefine the nature of customer engagement in a new scenario where customers will increasingly have access to distributed renewables and energy storage and opportunities to engage with third-party energy service providers, thus threatening the utility business model.

\subsubsection{For the Electric Power Sector}

The basic context for DSOs in Europe and the changes they are experiencing regarding their business models were already discussed in the introduction to this section. We have also reviewed good governance frameworks for renewable energy, ${ }^{122}$ although good governance of the electric power sector is much wider than just good governance regarding renewables. In IRENA's report on power system flexibility, the fact that flexibility in the system must respond according to the time scales that are relevant to renewable resources is explained. Many policies that support renewable energy, such as policies allowing for technologies adding flexibility in the market, were already reviewed in earlier sections of this chapter. Via the IRENA Knowledge Framework for power sector transition, IRENA has developed over twenty indicators allocated in the following macro-sectors (which indicate readiness for the energy transition): flexibility, transmission, demand response and storage, interconnectors, operation, and markets. More work is needed in each area to understand how new business models can apply in each case and which policies can be developed to support them. ${ }^{123}$

\footnotetext{
${ }^{121}$ IEA (2019e).

${ }^{122}$ Some elements of a good renewable energy governance for the electric power sector are highlighted in a report by IEA (2018b). According to the report, good governance of the energy transition should include: (1) renewable energy policies on end-use sectors, not just power generation, (2) support for heating and cooling applications of renewables by dedicated targets, technology mandates, financial incentives, generation-based incentives and carbon and energy taxes, (3) evolved policies in the power sector to address new challenges, (4) measures supporting the integration of variable renewable energy, and (5) consideration of holistic policies considering factors beyond the energy sector itself.

${ }^{123}$ IEA (2018b).
} 
There is also a need to consider reforming the basic model that allows for investments in the grid. This is also important to keep renewable energy sources, which may be produced at distance, connected to the grid. Some countries are better prepared for increasing renewables integration in their grids and others less. One of the ways to better adapt a regulatory framework in the energy sector for renewables is to adapt the cost allocation schemes of a country, sometimes allowing for very shallow cost allocation schemes for cost allocation structures associated with connecting renewable generation to the existing transmission network. Madrigal and Stoft review various structures already implemented in some European countries. ${ }^{124}$

\section{Insights from our Expert Workshop}

On 20 January 2020, we conducted a workshop with experts from different parts of the energy sector-in equal numbers with regard to the type of stakeholder-from start-ups to small and medium-sized enterprises (SMEs) to DSOs to academics and consultants in the energy sector. In order to facilitate the workshop and allow for an open discussion of the results, 15 participants were invited to the workshop and finally 12 participants and two organizers were present. The ideation workshop took place over three hours and was comprised of a quick introduction to our work followed quickly by four break-out working sessions. In these sessions, the participants worked on different tasks. First, they worked on what they individually thought were the conditions for an energy transition in general and shared this with their group. Second, they identified (using post-its) the conditions in the short term versus the long term as well as conditions necessary for Switzerland versus other countries-organizing the thoughts from the first brainstorming session and categorizing them on the chart we drew on the white board. In these first two breakout groups, both groups followed the same task and their results were combined later on. Then groups were asked to mix again and work together to discuss the conditions for incumbents to create business model reconfiguration in a more detailed manner (in one group). The other group was asked to consider the conditions for start-ups, SMEs, and new entrants to bring new business models or business model innovation to the sector. Participants were also asked to provide measurable indicators that could be used in our research work for the building of our Energy Transition Preparedness Index.

The participants always worked in two groups with participants mixing each time a new task was started to form a new group dynamic and in order to mix expertise and create a maximum level of creative potential for each of the topics addressed. Finally, they were asked to divide again into new groups in order to provide their inputs on new sources of data that we can use for developing measurements or

${ }^{124}$ Madrigal and Stoft (2012). 
indicators. Another group discussed methodologies that could be used to advance the research framework that had already been prepared by the research group.

The results of this workshop clearly showed that participants from across the value chain or ecosystem and across industries believed that policies were a key condition for driving business model change. Many policy options were suggested in the first and second brainstorming sessions. Both groups generated a diversity of policy suggestions to drive an energy transition. However, the most important findings for our research work concerned the conditions for business model reconfiguration versus business model innovation for start-ups and new entrants. These inputs will serve to inform the development of the Energy Transition Preparedness Index that we are building at HEIG-VD.

\subsection{Energy Transition Pre-Requisites Based on Time and Country/Region Context}

Time elements (such as the short term versus the long term) and space elements (such as geographical space considered) affect the assumptions one makes when considering what is needed for any given energy transition. From the workshop session on the time versus space perspective, Table 1 presents the combined results based on the time elements and space elements. We asked participants to note what were elements creating preparedness for an energy transition in each context and to try to indicate aspects that could be measured (as well as propose real indicators that could be used in our index).

\subsection{Changes Needed to Support Business Model Reconfiguration}

The key elements that participants viewed as important in terms of impacting business model reconfiguration were:

- lobbies (size, power, motivation)

- R\&D investments

- country energy mix (production)

- organizational structure and impacts of companies (aspects such as culture, turnover, organizational structure, energy footprint, environmental impacts of plants and production)

What we learned from this was that especially a measure for lobbies in a country had not been taken into account in our preparation of the Energy Transition Preparedness Index. We will have to find a value or proxy for measuring the 
Table 1 Elements important for an energy transition ${ }^{\mathrm{a}}$

Selected elements important for Switzerland

Elements important in the short term:

- pilot projects with new tech \& business

models

- spending on renewable research

- consciousness of people

- financial incentives

- cheaper rail travel

- technology to limit reinforcement of the electricity grid (maximize assets)

- legal framework

Elements important in the long term:

- preventing PV cannibalization (maintaining longterm profitability)

- geopolitical independence

- recycling infrastructure for $\mathrm{PV}$

- personal energy management conducted by residential consumers in the same way as financial management (user-friendly)

- the financial sustainability of the energy transition model

Elements important for all countries

Elements important in the short term:

- policies to push renewables

- regulation on the use of gas

- push full EVs (not plug-in hybrids)

- EU regulation for charging infrastruc-

ture at home

- road tax for EVs not before 2026

- $\mathrm{CO}_{2}$ standards for new vehicles sold

- battery-powered trains

- country-level investments in Distributed

Energy Resources (DER) roll-out

- digitalization vision at country level

- change management inside of firms

- consumer evolution towards prosumers

- political consensus to move away from

"dirty" production
Elements important in the long term:

- get out of fossil fuel energies (coal, fuel)

- lower $\mathrm{CO}_{2}$ everywhere with incentives

- competitive pressure on energy distributors (create urgency to act)

Things that can be measured:

- renewable installed capacity (power and heat generation)

- tech innovation around energy production,

exchange, local consumption

- availability of new technologies for production and

distribution

- legal and regulatory framework (e.g., updated

norms, incentives for housing refurbishment ...)

- charging infrastructure and other key infrastructure

investments

- education to raise awareness and social

responsibility

${ }^{a}$ Based on the initial brainstorming by workshop participants on January 20, 2020 at HEIG-VD in Yverdon-les-Bains, Switzerland

power of lobbies eventually, but in the meantime, we could use the SDG Index to obtain measures for good governance.

\subsection{Changes Needed to Support Business Model Innovation}

The key changes that participants viewed as important for creating the conditions for business model innovation (for start-ups, SMEs and new entrants) were:

- grants and funds available for start-ups

- good universities = universities that produce a lot of entrepreneurs

- number of organizations that bridge start-ups and industry

- number of start-ups met by incumbent companies

- number/value of angel investors in energy 


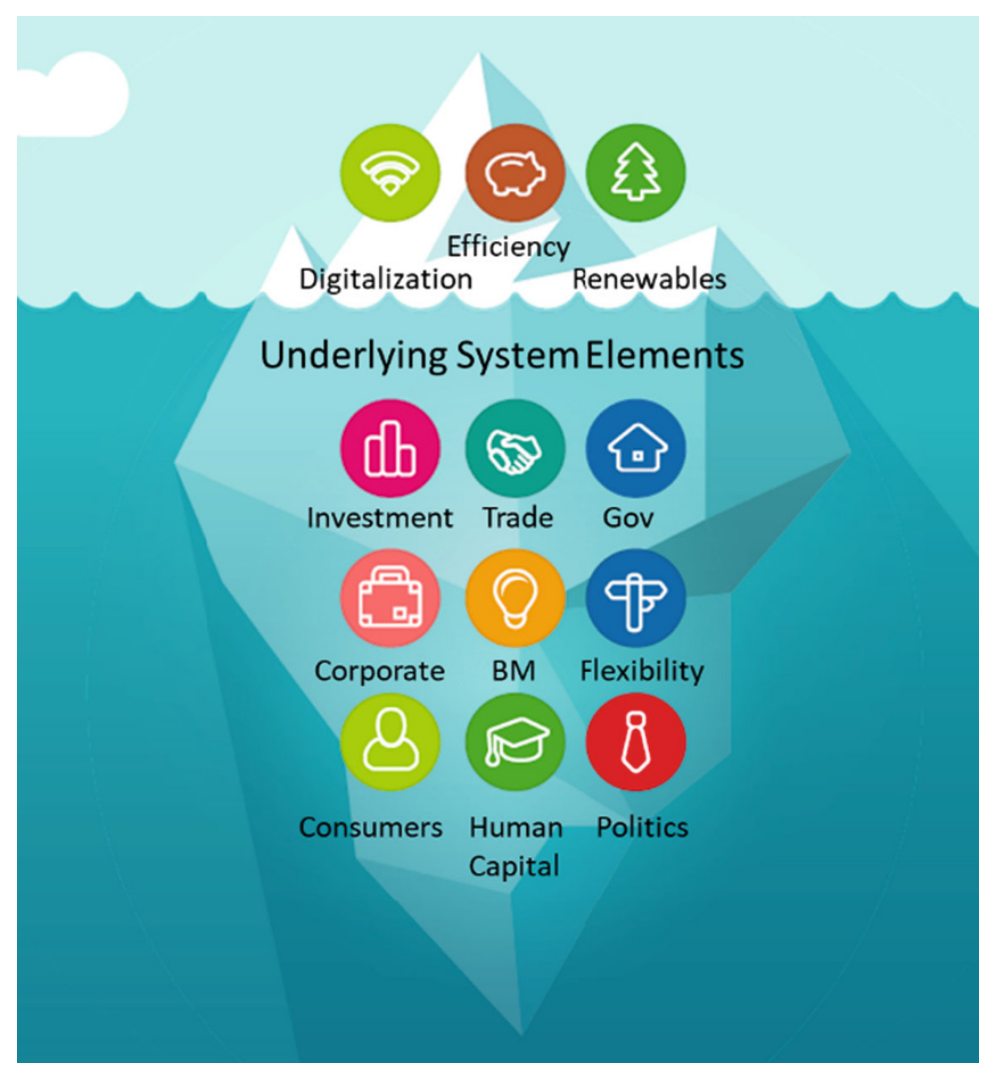

Fig. 1 Elements of an energy transition and its interacting systems

- funded mentors

- number of policies promoting innovation and helping to add urgency

Participants strongly believed that SMEs and start-ups must receive support to bridge the gap towards incumbents and that rather simple solutions such as increased numbers of mentors to link start-ups to incumbents could help in this respect. With regards to quantification and measurement of preparedness, the quality of mentorship (and other) programs will, however, be difficult to estimate.

In any case, the full results of this session combined with the knowledge we have gained from our ongoing database development will help us develop three sub-indexes of the Energy Transition Preparedness Index:

- Sub-Index 1: Comparing countries by their general infrastructure and investments

- Sub-Index 2: Comparing countries by antecedents for business model reconfiguration (for incumbents)

- Sub-Index 3: Comparing countries by antecedents for business model innovation (for start-ups, SMEs, and new entrants) 


\section{Additional Considerations for Good Governance of an Energy Transition}

\subsection{The Contribution of the Finance Sector}

Between the adoption of the Paris Agreement in 2016 and the end of 2018, cumulative bank finance for fossil fuels amounted to $\$ 1.9$ trillion. Global subsidies for fossil fuel consumption reached an estimated $\$ 300$ billion in 2017 , an $11 \%$ increase from the $\$ 270$ billion in the year before and about double the estimated support for renewable power generation. ${ }^{125}$ In addition, one estimate places the true cost of fossil fuels at upwards of $\$ 5.2$ trillion. ${ }^{126}$ Meanwhile, rich developed countries, including European countries, continue to invest in dirty energy projects around the world via export credit agencies. According to a review on financing for dirty energy projects, export credit agencies (ECAs) from G20 countries were responsible for $\$ 5.6$ billion in annual support for coal projects between 2013 and 2015 or $57 \%$ of all public finance for coal. ${ }^{127}$

With regard to carbon pricing, the report explains in some detail that recognizing the cost of carbon emissions, governments are working on pricing carbon so that the market internalizes this cost and investment decisions are made accordingly. Meanwhile, public finance for the production of fossil fuels effectively acts as a negative price on carbon emissions. This is why reforming ECAs should happen in parallel to putting in place carbon pricing schemes around the world.

According to the WEF, the "rapid approach" to the energy transition does not deny that fossil fuels will continue to play a major role in energy markets for decades to come. ${ }^{128}$ Growth in the core markets of major energy players may turn to decline and the effects may be priced by financial markets even before supply peaks. Moreover, the report explains that once a tipping point is reached, financial markets will tend to speed up the pace of change by constraining capital to declining industries and reallocating it to those that are growing. Moreover, regulations will most likely eventually change to reduce the lawsuits of companies and even stateowned companies against countries for their abrupt legal decisions regarding the energy transition. ${ }^{129}$ But, of course, these effects do not happen alone. They happen

\footnotetext{
${ }^{125}$ IISD (2017).

${ }^{126}$ REN21 (2019a).

${ }^{127}$ According to Doukas et al. (2017), p. 4, a few country actors are responsible for the majority of this financing, with Japan and China in particular standing out along with South Korea and the United States. The report states that "Japan is the largest provider of public finance for fossil fuels for both oil and gas, and coal - with $\$ 16.5$ billion annually in support between 2013 and 2015 compared to $\$ 2.7$ billion annually in support for clean energy."

${ }^{128}$ WEF (2019c).

${ }^{129}$ In a blog by IISD, the Energy Charter Treaty and its implications on countries wishing to change laws affecting investments in the nuclear or coal sector are explained (IISD 2019).
} 
because of a concerted effort to get to the root of the problem-the way fossil fuels are financed and the level of investments in this sector.

Today countries can instead invest in green bonds and other green financial instruments with public money, while they reduce their investments in dirty energy projects. Green finance centers are emerging everywhere in the world from New York to London originally and to countries like South Africa, Morocco, Kazakhstan, and others today. Africa is expected to attract significant green investment as it starts to build up solar and wind power, taking advantage of the opportunity to leapfrog outdated fossil fuel energy systems. International banks are also moving ahead with green finance such as France's Credit Agricole that has surpassed Spain's Banco Santander recently for being the top underwriter of green bonds this year. France and China are contending as the biggest backers of green bonds in 2019 and 2020. As countries are increasingly decarbonizing their investments and the same time shifting to green finance and allowing local finance centers to emerge to finance infrastructure projects at the local level, things will start to change. ${ }^{130}$

\subsection{Consumption Patterns}

The role of European countries' production and consumption patterns in contributing to the current state of planetary boundary ${ }^{131}$ processes is a starting point to measure and assess how countries, or a given country, are doing with regard to their current state of production and consumption and how they are doing with regard to addressing this issue seriously. Input-output analyses combined with life-cycle analyses are another method to understand the contribution of production and consumption patterns of a country to various environmental issues. The level of consumption in Switzerland is already high compared to other countries in the world. The Swiss government is fully aware of this problem. The Swiss Federal Office for the Environment (FOEN) notes that the global impacts of Swiss consumption are primarily at the expense of the climate and biodiversity. ${ }^{132}$ In terms of climate change, Switzerland's per-capita greenhouse gas footprint is currently around 14 tonnes of $\mathrm{CO}_{2}$-equivalents per capita, well above the globally sustainable level, which scientific estimates place at 0.6 tonnes per capita for $2015 .{ }^{133}$ If one also counts the impact of the financial sector, one of the country's biggest economic engines, one can calculate an even bigger footprint for Switzerland, compared to other countries. The point, however, is not to criticize Switzerland but rather to underline that any country's energy transition goals cannot be achieved (no matter

\footnotetext{
${ }^{130}$ Bloomberg (2019).

${ }^{131}$ Rockström et al. (2009).

${ }^{132}$ Swiss Federal Office for the Environment (2019).

${ }^{133}$ FOEN website (accessed in February 2020): https://www.bafu.admin.ch/bafu/fr/home/themes/ economie-consommation/dossiers/impact-environnemental-du-commerce-international.html.
} 
what technologies and business models are applied) without significant changes in consumption patterns. ${ }^{134}$

Population growth, economic growth, and the fact that Swiss consumption has risen disproportionately to population growth are among the key drivers and trends responsible for the situation. The Swiss Federal Office for the Environment explains that between 2000 and 2016, household consumption spending increased by $31 \%$, almost twice as much as the population. At the same time, consumption patterns have worsened due to open market policies. ${ }^{135}$

Work reviewing transport consumption patterns for cities and urban areas is also available for various countries, and from this work it is clear that emissions from transport continue to be a major problem for most countries, in particular growth in emissions from passenger vehicles. To solve this problem, countries can consider recommendations for city planners to reduce emissions while making cities more livable for citizens. This is one way to deal with this type of consumption pattern, although one that is very challenging. For example, a set of recommendations is available in Kodukula (2018). ${ }^{136}$

More efficient, cost-deflated energy unlocks new consumption patterns. In the past, when a new energy source entered the global energy mix, there was an acceleration of energy demand. ${ }^{137}$ In the future, it would be interesting to understand how new business models could help reduce energy demand along with revolutions on the supply side. Which business models offer benefits on both sides of the equation and what are the key policy-making solutions that would push such business models to become commonplace?

Also, while a country can reduce its consumption based on business-as-usual consumption patterns, policymakers must be aware that new scenarios can also lead to some increases in consumption due to new consumption patterns. In fact, some new business models may even lead to higher consumption, while others lead to unexpected changes in consumption behavior. More research would be needed to understand what the potential effects could be of various new business models. For example, blockchain-based business models in the energy sector could be overall beneficial in one way, but they could increase emissions on the other hand (perhaps emissions generated elsewhere) because of the architecture choices for blockchain (e.g., proof of work being the most energy-intensive choice). ${ }^{138}$

\footnotetext{
${ }^{134}$ Cassoret (2018).

${ }^{135}$ The environmental impact of opening up the market was reviewed by the Swiss Federal Office for the Environment (see Frischknecht et al. 2018). It mentions that in the context of international trade, the environmental impact of consumption is felt throughout the production and marketing chains, as shown by the example of Switzerland, which generates the largest part of its impact (more than $70 \%$ ) abroad. The Swiss Federal Office for the Environment explains that for trade to be genuinely sustainable from an ecological point of view, producing countries should have environmental laws comparable to those of Switzerland-and respect them.

${ }^{136}$ Kodukula (2018).

${ }^{137}$ Fattouh et al. (2019).

${ }^{138}$ Bürer et al. (2019).
} 
Table 2 Components of the energy transition preparedness index and interacting systems

\begin{tabular}{|c|c|}
\hline Groups of elements & Components for the development of indicators \\
\hline $\begin{array}{l}\text { Tip of the Iceberg (elements } \\
\text { often tracked already) }\end{array}$ & $\begin{array}{l}\text { - energy efficiency progress (for various sub-sectors) } \\
\text { - renewable energy progress (for various sub-sectors and } \\
\text { using various indicators) } \\
\text { - digitalization preparedness and management of digitalization } \\
\text { trends }\end{array}$ \\
\hline Energy-Economy System & $\begin{array}{l}\text { - capital and investment } \\
\text { - trade: exports (net exports of } \mathrm{CO}_{2} \text {, but also embodied } \mathrm{CO}_{2} \text { in } \\
\text { exports) and also indicators for imports } \\
\text { - institutions and governance with a focus on innovative } \\
\text { activities and programs for both industry and start-ups } \\
\text { together }\end{array}$ \\
\hline Energy-Tech/Business System & $\begin{array}{l}\text { - corporate commitment } \\
\text { - innovative business environment supported for both busi- } \\
\text { ness model innovation and business model reconfiguration } \\
\text { - energy system structure including production (e.g., storage } \\
\text { and flexibility of system for renewable energy) }\end{array}$ \\
\hline Energy-Society System & $\begin{array}{l}\text { - consumer participation } \\
\text { - human capital } \\
\text { - regulation and political commitment (including whether they } \\
\text { address systemic issues) }\end{array}$ \\
\hline
\end{tabular}

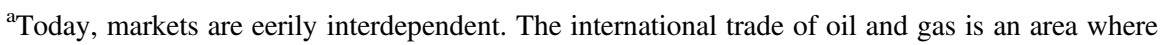
one country's self-interested strategy can have dramatic impacts on the entire world economy and the environment in general

\subsection{Building an Energy Transition Preparedness Index}

Based on our own work on the Energy Transition Preparedness Index, ${ }^{139}$ we have defined the following key areas that we want to cover in our index. They are grouped by interacting systems (Table 2).

Using this basic framework, an Energy Transition Preparedness Index can be prepared with a variety of data sources and indicators from existing indexes around the world to compare countries on their energy transition progress to date. For each of the areas above, data and indicators can be aggregated with regard to different aspects such as clean energy, energy efficiency, mobility, climate and energy data, fossil fuels/nuclear power, and general economic or industrial policy indicators. A "country scorecard" is envisioned, which can provide an explanation of a country's ranking and suggestions on how it can improve. As for companies, a "company

\footnotetext{
${ }^{139}$ This work commenced in 2014 and it is ongoing. It includes (1) semi-structured interviews with executives and middle managers in the energy sector; (2) our own case study analysis of sub-sectors like on-grid storage, smart grid technologies, and microgrids; (3) an analysis of what we have discovered from existing energy transition assessment work and our literature review; (4) data collection and initial development of the index; and (5) an analysis of workshop results (one workshop on blockchain use cases in the energy sector held in June 2019 and another workshop on the index held in January 2020).
} 
scorecard" can also be used to compare how prepared a company is compared to others in the given industry segment. Such scorecards could help both countries and companies monitor their progress on the energy transition and provide an incentive to improve over time. They can also be used to evaluate weaknesses in any given system and to understand how changes in one system might also influence other elements in the same interacting system or in another interacting system, or another country altogether. The emphasis of our scorecards will, however, be on business model transformation elements, meaning that part of the data collected and used for the work will have to be qualitative, not only quantitative or based on existing data and indicators from well-known sources.

For each country, each interacting system should be evaluated using all available data to the greatest extent possible. Once the results are available, weaknesses in any interacting system can be identified. How these weaknesses may influence other interacting systems can also be discussed. The objective of the index will be to create an open discussion about countries' key energy transition choices, based on scientific evidence.

Based on our analysis until now, we can say at least that top ranked countries in such an assessment should ideally have the following characteristics:

1. The country has effective governance of the energy transition-for example, the governance is transparent, participatory and resilient from (or less affected by) lobbying pressures. The country feels free to change its decisions on energy without fearing legal challenges. It has already made important capital and R\&D investments towards supporting clean energy and transport and demonstrates a low carbon energy system compared to others. The country also shows constant improvement and verifiable action plans to move towards zero emissions in all areas and in cooperation with various stakeholders.

2. The country (and participating companies) actively invests in creating an innovative business environment in all sub-sector areas with a focus on innovation for a purpose, as opposed to innovation only for economic growth. Purpose-led missions are a means towards meeting economic objectives as well as environmental or social objectives of a country. The country has shown to be innovative in its governance framework conditions, and policies are made to evolve rapidly with technological and new business model opportunities. For example, the country allows sandboxes or specific temporary measures (aimed at supporting the emergence of innovative business models) in its regulatory framework. ${ }^{140}$

3. The country is not only investing in support mechanisms and programs for new business models and innovative technologies in the area of clean or low-carbon energy production, but also in the areas of energy productivity of industrial processes and buildings performance.

\footnotetext{
${ }^{140}$ An example is the co-ownership law scheme in Switzerland (RCP in French and ZEV in German) that provides a legal basis for self-consumption communities and allows for different tariff structures inside the community (from the normal regulated tariff structures).
} 
4. The country already has a flexible energy system and is working to make it more flexible to allow for the increasing inclusion of renewables while fostering energy efficiency in all application domains in parallel with efforts to encourage the implementation of network convergence and sector coupling solutions.

5. The country is also active in addressing systemic roots of the problem, including consumption patterns of the population and the impact of financial institutions' investment decisions (especially for countries where the financial sector is important, like Switzerland). This means that the country has demonstrated its intentions through deeds and actions and it has displayed good governance in these two areas.

6. The country displays a high level of corporate engagement either via its private sector associations and/or via individual corporate leadership actions. Corporate commitment is demonstrated via indicators and data gathered by neutral parties.

7. The country also displays a high level of local leadership from cantons, cities, communes, and even schools with their individual activities and programs to include and involve citizens in the energy transition.

8. The country displays evidence of investing in human capital to address the energy transition, with a focus on supporting start-ups and entrepreneurs not only with technological innovations but also with business model innovations for the energy sector. The number of events that connect start-ups to incumbents is one indicator. Investments in programs that connect start-ups with incumbents in the energy sector and allow for mentoring start-ups that are introducing new business models and technologies, including digital innovations, are also important.

9. The country has a sufficient level of digital competitiveness, and it has plans and programs for the use of digital technologies towards strategic energy transition goals. At the same time, it is addressing increasing energy use from data centers, data networks, etc.

10. The country's spending on public transportation is sufficient and public satisfaction with public transport is high. Important investments such as electrified railway lines or other low-carbon means of transportation have been realized. Planning also integrates the interaction between transport and land use. The country also continues to support innovative concepts and business models for mobility.

The underlying systems represented in this figure are:

1. Energy-economy system: investment, trade and institutions/existing governance

2. Energy-technology/business system: corporate, business model innovation and reconfiguration, and flexibility of the energy system

3. Energy-society system: consumer participation, human capital, and regulatory and political commitment (including regulating and using the financial system appropriately)

These three systems and the underlying indicators and data sources for each will be compiled in the three sub-indexes explained earlier, allowing primarily for the 
above elements to be combined appropriately depending on which stakeholder the elements apply to (incumbents or start-ups, SMEs, and new entrants).

Metrics for each of the areas above now need to be developed based on available qualitative and quantitative data and integrated in a meaningful way. One way is using systems thinking which can then be used later for stakeholder value network analysis and other useful tools for the development of strategies. It is also important to understand which systems different players have control over in order to change them. In the World Economic Forum's work on the energy transition, three co-evolving and interacting systems were defined: (1) energy-economy, (2) energy-technology, and (3) energy-society. ${ }^{141}$

One could imagine an index developed for each system so that we can compare countries by interacting systems as well as elements relevant to each type of business model change. The results can then be compiled into one index for a general comparison. What is important to remember, however, is that the elements we will be measuring are not independent; they are interdependent, and this adds another challenge when building such an index.

However, if successful with such an approach, we can at least begin the process of uncovering all the elements hidden under the "tip of the iceberg" of energy transition assessments. Eventually specific companies' strategic responses to the energy transition can be analyzed using this tool as well.

\section{Conclusions on Governing the Energy Transition via Business Model Change}

In our research work conducted over the past years, we have aimed to understand business model transformation in the energy sector via a mix of methods. All governments must start working closely together with their business community members in innovative and transparent ways towards developing necessary regulatory frameworks and other means to promote and take the maximum advantage from new business models and new technologies. Each country (and community) will have its own pathway to finding the most appropriate solutions and investing in them. For an effective energy transition, new business models should be supported in the area of renewable energy integration but also in the areas of energy productivity of industrial processes and buildings performance. New or reconfigured business models must also address the problem of consumption patterns.

\footnotetext{
${ }^{141}$ WEF (2019a), p. 23, covers the three co-evolving and interacting systems above. For example, in the energy-society system the focus is on the collection of energy policies related to efficiency, security and energy equity/justice. The key players identified for this system are policymakers, consumers, and workers. The challenges identified for this system comprise competing priorities within different political parties and governments and changes in priorities over different time frames.
} 
Indeed, this chapter shows that alternative business models are moving away from energy as a commodity (the push model) to energy as a service, where an end-customer can partner with (or replace) the provider. However, not all countries' energy sectors will evolve rapidly towards such business model transformation. Countries will proceed at different paces and should proceed at different paces, due to varying priorities. Apart from those higher-level insights, from our analysis of data and our workshop findings we have found that for an energy transition to happen many elements need to be put in place. In all areas, business model innovation and reconfiguration can play a huge role in creating the transition towards cleaner sources of energy. From our analysis, technological innovation, such as from digitalization, is also shown to provide future value to energy transitions, providing new opportunities for energy efficiency, new ways to trade and manage energy, and new strategies for a better management of the grid.

However, we also discussed that new technologies and business model transformation are not enough. Consumption patterns need to change as well and perhaps business models can help in that respect, but not on their own. New educational programs could be envisaged, youth could be more empowered to find innovative solutions through specific design thinking challenges and similar initiatives. These events could be co-sponsored by universities, companies, and other groups such as investors. However, whatever funding is available should require concrete results as well. The focus of such events should not only be on technological solutions, but mentors and coaches are needed to orient students, entrepreneurs, and professional participants towards thinking about how to use technologies in existing systems or how to combine multiple sources of energy. Design thinking sprints should not stop at the ideation stage, but they should allow for sufficient product demonstration and testing, or business model development and testing. Eventually the best ideas can then move on to deployment and testing in the market.

We have also learned that good energy transition governance is not only about pushing forward renewable energy investments and deployment of renewable energy to its maximum or about applying taxes, but it requires smart integrated policies and policies that address the systemic problems, such as the financial system, and consumption patterns. The latter are a kind of third generation of energy transition policies. New strategies for policy-making, participatory methods for policy development, and innovation with a purpose are required. Strategies must be increasingly developed by multiple stakeholders of society, and progress (or setbacks) and commitments by both the public and the private sectors should be monitored in a transparent and unbiased manner. That calls for new approaches based on open governance, co-creation, design thinking, and agile innovation on the part of governments, among incumbents, between institutions, and not only among start-ups.

Meanwhile, there is no perfect scenario and there is no perfect pathway to the energy transition of a country, just as there is no perfect country comparison. However, it is clear that more research and a better understanding are needed with regard to what governance frameworks inspire business model reconfiguration among incumbents on the one hand and business model innovation from start-ups 
and new entrants on the other hand and how these two phenomena influence each other. Dealing with the energy transition is extremely complex for a number of reasons. However, this complexity should not bar us from trying. A saying says: "Do not fear failure but rather fear not trying" (Roy T. Bennett).

\section{Ideas for Future Research}

Some ideas for future research that would appear to be valuable given our analysis of what is available today and what is missing are:

- Understand the systemic impacts of recent events on the energy transition and how far the power of new business model innovation can go in driving us towards an energy transition in each country context.

- Evaluate alternative ways to compile and compress all the relevant energy transition indicators into one measurement tool and allow the tool to generate different results based on the users' own opinions about each possible input to avoid bias.

- Look at what people are doing in each country: How are social movements affecting the energy transitions of different countries and how can the energy transition be managed in a democratic way, helping to increase the sense of cohesion of societies in a time of potential global unrest?

- Look into what people want from their energy transition (how this is different in countries), perhaps clustering countries by people's expectations for their energy transition.

- Produce more case studies to understand business model changes per sub-sector and the way policies are barring or promoting such developments in each case.

- Do more research on which business models offer benefits on both sides of the equation (the demand side as well as the supply side) and on the key policymaking solutions that would push such business models to become commonplace.

- How can public sector entities develop new business models themselves, and how can unprecedented changes be imagined by local leaders to significantly change business models on the local level?

- Carry out more interviews with executives to understand what makes their companies able to change their existing business models and what they think about regulations and legislation which could support business model developments for the energy transition, despite external shock factors such as a global oil price shock.

- Analyze the impact of energy transition pathways on people and how people in turn may impact the pathways, e.g., consider how young people are changing their consumption habits or modes of transport and how this will impact different sub-sectors and scenarios. 
- Hold more design thinking workshops between different players-government, businesses, and even consumers - to work together on these issues and find solutions community by community.

Acknowledgements The authors are particularly grateful to the companies that kindly accepted to participate in this study via our design thinking workshop held in January 2020 and in the interviews, which we conducted with executives of companies in the energy sector inside and outside of Switzerland since the start of SCCER CREST in 2014.

\section{References}

Ali Y (2019) Sweden's Summer Sunshine Stored in Hydrogen for the Winter. Microgrid Knowledge, 17 December 2019. Available at https://microgridknowledge.com

Ali A, Li W, Hussain R, He X, Williams BW, Memon AH (2017) Overview of current microgrid policies, incentives and barriers in the European Union, United States and China. Sustainability 9(7):1146. https://doi.org/10.3390/su9071146

Bade G (2018) Storage will replace 3 California gas plants as PG\&E nabs approval for world's largest batteries. Utility Dive, 9 November 2018. Available at https://www.utilitydive.com

Bloomberg (2019) The Rise of the Green Financial Hubs. Bloomberg Green, Newsletter by Bloomberg, 4 March 2020. Available at https://www.bloomberg.com

Boo E, Dallamaggiore E, Dunphy N, Morrissey J (2016) How innovative business models can boost the energy efficient buildings market. Int J Housing Sci Appl 40(2):73-83

Boo E, Molinero S, Sanvicente E, de Melo P, Landini A, Otal J, Melchiorre T, Melia A (2017) Report on novel business models and main barriers in the EU energy system, report for the ENTRUST project, January 2017

Bousso R (2018) Big Oil spent 1 percent on green energy in 2018. Reuters, 12 November 2018. Available at https://www.reuters.com

Broeckx S, Ramos A, Fernandez L, Meeus L (2019) Energy Storage - Our take on business models and regulation. STORY, A vision of our future energy system, Horizon 2020 project. Story Highlight, May 2019

Bürer M, de Lapparent M, Pallotta V, Capezzali M, Carpita M (2019) Use cases for blockchain in the energy industry opportunities of emerging business models and related risks. Comput Ind Eng 137. https://doi.org/10.1016/j.cie.2019.106002

Burger SP, Luke M (2016) Business models for distributed energy resources: a review and empirical analysis. An MIT Energy Initiative Working Paper, April 2016. Massachusetts Institute of Technology, USA

Cassoret B (2018) Transition énergétique - Ces vérités qui dérangent! De Boeck Supérieur, Paris

Castaneda M, Franco CJ, Dyner I (2017) Evaluating the effect of technology transformation on the electricity utility industry. Renew Sust Energ Rev 80:341-351. https://doi.org/10.1016/j.rser. 2017.05.179

CEC (2018) Microgrid Analysis and Case Study Report, California, North America and Global Case Studies, August 2018. Navigant Consulting, Chicago

Cross S, Hast A, Kuhi-Thalfeldt R, Syri S, Streimikiene D, Denina A (2015) Progress in renewable electricity in Northern Europe towards EU 2020 targets. Renew Sust Energ Rev 52 (C):1768-1780

CPLC (2020) Who is using carbon pricing? Carbon Pricing Leadership Coalition. Available at https://www.carbonpricingleadership.org/who 
Diestelmeier L (2019) Changing power: shifting the role of electricity consumers with blockchain technology - policy implications for EU electricity law. Energy Policy 128:189-196. https://doi. org/10.1016/j.enpol.2018.12.065

DIREN (2019) Conception cantonale de l'énergie, Adoptée par le Conseil d'Etat le 19 juin 2019, Canton of Vaud, DTE, DGE, DIREN

Doukas A, DeAngelis K, Ghio N (2017) Talk is Cheap: How G20 Governments are Financing Climate Disaster, July 2017. Oil Change International, Friends of the Earth U.S., the Sierra Club, and WWF European Policy Office. Available at http://priceofoil.org

Duygan M, Kachi A, Oeri F, Oliveira TD, Rinscheid A (2021) A survey of stakeholders' views and practices. In: Hettich P, Kachi A (eds) Swiss energy governance. Springer, New York, pp 369-396

Ebers Broughel A, Wüstenhagen R (2021) The influence of policy risk on swiss wind power investment. In: Hettich P, Kachi A (eds) Swiss energy governance. Springer, New York, pp 345-368

European Commission (2019) EU Transport Scoreboard. EU mobility indicators for years 2015-2017. European Commission. Available at https://ec.europa.eu

Facchinetti E, Eid C, Bollinger A, Sulzer S (2016) Business model innovation for local energy management: a perspective from Swiss utilities. Front Energy Res 4. https://doi.org/10.3389/ fenrg.2016.00031

Fattouh B, Poudineh R, West R (2019) The rise of renewables and energy transition: what adaptation strategy exists for oil companies and oil-exporting countries? Energy Transit 3:45-58. https://doi.org/10.1007/s41825-019-00013-x

FFE (2020) Value of flexibility in the context of European electricity market coupling with extreme technological, regulatory and social developments. The Research Center for Energy Economics, Munich. Available at https://www.ffe.de

Frischknecht R, Nathani C, Alig M, Stolz P, Tschümperlin L, Hellmüller P (2018) UmweltFussabdrücke der Schweiz - Zeitlicher Verlauf 1996-2015. Federal Office for the Environment, Bern

Gancheva M, O’Brien S, Crook N, Monteiro C (2018) Models of local energy ownership and the role of local energy communities in energy transition in Europe. Report for the Commission for the Environment, Climate Change and Energy, European Committee of the Regions, Brussels

GLI (2020) Energy Laws and Regulations - Switzerland. In: GLI - Global Legal Insights International legal business solutions. Available at https://www.globallegalinsights.com

Gately D (1986) Lessons from the 1986 oil price collapse. Brook Pap Econ Activity 17:237-284

Hedstrom GS (2019) Beware the 80/20 Governance Trap: Focus on the "G" in ESG. Available at https://esgnavigator.com

IEA (2017) Changing utility business models and electricity investment. IEA, Paris

IEA (2018a) World energy investment 2018. IEA, Paris. Available at https://www.iea.org

IEA (2018b) Renewable Energy Policies in a Time of Transition. IRENA, OECD/IEA and REN21

IEA (2019a) Energy Transitions Indicators. Tracking energy transitions. IEA, Paris, 2 December 2019. Available at https://www.iea.org

IEA (2019b) Tracking Power. IEA, Paris. Available at https://www.iea.org

IEA (2019c) Energy Efficiency 2019. IEA, Paris. Available at https://www.iea.org

IEA (2019d) Shared, automated... and electric? Commentary 28 March 2019. IEA, Paris. Available at https://www.iea.org

IEA (2019e) Global EV Outlook 2019. IEA, Paris. Available at https://www.iea.org

IEA (2020) Germany 2020 - Energy Policy Review. Country report - February 2020. IEA, Paris. Available at https://www.iea.org

IISD (2017) Fossil Fuel Subsidy Reform and Taxation- Stories for Success for the Talanoa Dialogue. IISD Global Subsidies Initiative submission to the UNFCCC Talanoa Dialogue, March 2017. Available at https://unfccc.org

IISD (2019) Modernizing the Energy Charter Treaty: A make-or-break moment for sustainable, climate-friendly energy policy, by Martin Dietrich Brauch, 13 November 2019. Available at https://www.iisd.org 
IRENA (2018) Power system flexibility for the energy transition, Part 1: overview for policy makers. International Renewable Energy Agency, Abu Dhabi

IRENA (2019a) Innovation landscape for a renewable-powered future: solutions to integrate variable renewables. International Renewable Energy Agency, Abu Dhabi. Available at https://www.irena.org

IRENA (2019b) Renewable Energy Statistics 2019 and Renewable Capacity Statistics 2019. International Renewable Energy Agency, Abu Dhabi. Available at https://www.irena.org

IRENA (2019c) Solutions to integrate high shares of variable renewable energy (Report to the G20 Energy Transitions Working Group (ETWG)). International Renewable Energy Agency, Abu Dhabi. Available at https://www.irena.org

Kodukula S (2018) Integrated land use planning and Urban transport in low carbon cities. UNCRD Environmentally sustainable transport (EST) forum. Ulaanbaatar, Mongolia

Lafortune G, Zoeteman K, Fuller G, Mulder R, Dagevos J, Schmidt-Traub G (2019) The 2019 SDG Index and Dashboards Report for European Cities (prototype version). Sustainable Development Solutions Network (SDSN) and the Brabant Center for Sustainable Development (Telos)

Liu Q (2018) The next economic crisis could cause a global conflict. Here's why. World Economic Forum, 13 November 2018. Available at https://www.weforum.org

Loock M (2012) Going beyond best technology and lowest price: on renewable energy investors' preference for service-driven business models. Energy Policy 40:21-27

Madrigal M, Stoft S (2012) Transmission expansion for renewable energy scale-up: emerging lessons and recommendations, A World Bank Study. World Bank, Washington, D.C. Available at https://openknowledge.worldbank.org

Massa L, Tucci CL (2014) Business model innovation. In: Dodgson M, Gann DM, Phillips N (eds) The Oxford handbook of innovation management. Oxford University Press, Oxford, pp 420-441. https://doi.org/10.1093/oxfordhb/9780199694945.013.002

Mediavilla M, de Castro C, Capellán I, Javier Miguel L, Arto I, Frechoso F (2013) The transition towards renewable energies: physical limits and temporal conditions. Energy Policy 52:297-311. https://doi.org/10.1016/j.enpol.2012.09.033

Montgomery S (2020) The oil shock of 2020 appears to be here - and the pain could be wide and deep. In: theconversation.com, 13 March 2020. Available at https://theconversation.com

Monzon D, Guzman R, Kalkman J, Rogers S, Kinbaum A (2019) Shaping the oil company of the future. Arthur D Little Prism 1(2019):56-71. Available at https://www.adlittle.com

Navigant (2019) Transportation-to-Grid - New Business models to capture value in the energy cloud, published in 2019. Available at https://www.guidehouse.com

NordREG (2018) Implementation of data hubs in the Nordic countries. Status Report, June 2018

Nouyrigat V (2019) Streaming, bitcoin, IA: le délire énergétique! Science \& Vie. Available at https://www.science-et-vie.com

NRF (2019) Regulatory progress for energy storage in Europe. Norton Rose Fulbright. Available at https://www.nortonrosefulbright.com

Osterwalder A, Pigneur Y (2010) Business model generation: a handbook for visionaries, game changers, and challengers. John Wiley \& Sons, Hoboken

Pojasek RB, Toolbox Q (2010) Quality toolbox using leading indicators to drive sustainability performance. Environ Q Manage 18(4):87-93. https://doi.org/10.1002/tqem.20228

Prettico G, Flammini M G, Andreadou N, Vitiello S, Fulli G, Masera M (2019) Distribution System Operators observatory 2018 - Overview of the electricity distribution system in Europe, EUR 29615 EN, Publications Office of the European Union, Luxembourg. https://doi.org/10.2760/ 104777, JRC113926

Przychodzen J, Gómez-Bezares F, Przychodzen W, Larreina M (2016) ESG issues among fund managers-factors and motives. Sustainability 8:1078. https://doi.org/10.3390/su8101078

REA (2019) Energy Transition Readiness Index, A new report from the REA, commissioned by Eaton and Drax. Available at https://www.r-e-a.net

REN21 (2019a) Renewables 2019 Global Status Report. Renewable Energy Policy Network, REN21 Secretariat, Paris. Available at https://www.ren21.net/ 
REN21 (2019b) Just Launched: Our Renewables in Cities 2019 Global Status Report. Renewable Energy Policy Network, REN21 Secretariat, Paris. Available at https://www.ren21.net

Reuters (2017) European utilities urge EU to raise green energy targets, 6 November 2017. Available at https://uk.reuters.com

Richter M (2012) Utilities' business models for renewable energy: a review. Renew Sust Energ Rev 16(5):2483-2493. https://doi.org/10.1016/j.rser.2012.01.072

Richter M (2013) Business model innovation for sustainable energy: German utilities and renewable energy. Energy Policy 62:1226-1237

Rieple A, Sorg M, Meier G (2019) Ziel 2030: Anteil erneuerbarer Gase 30\% im gasversorgten, Wärmemarkt für Gebäude, (1) Aktuelle Herausforderungen. Energie Zukunft Schweiz, Dezember 2019. Available at www.ezs.ch

Rockström J, Steffen W, Noone K, Persson Å, Chapin F, Lambin E et al (2009) Planetary boundaries: exploring the safe operating space for humanity. Ecol Soc 14(2):32. https://doi. org/10.5751/ES-03180-140232

Rubino A, Costa Campi MT, Lenzi V, Ozturk I (eds) (2016) Regulation and investments in energy markets. Elsevier, Academic Press. https://doi.org/10.1016/C2015-0-00384-7

Sachs J, Schmidt-Traub G, Kroll C, Lafortune G, Fuller G (2019) Sustainable development report 2019. Bertelsmann Stiftung and Sustainable Development Solutions Network (SDSN), New York

Schaltegger S, Lüdeke-Freund F, Hansen E (2012) Business cases for sustainability: the role of business model innovation for corporate sustainability. Int J Innov Sustain Dev 6:95-119. https://doi.org/10.1504/IJISD.2012.046944

Schleicher-Tappeser R (2012) How renewables will change electricity markets in the next five years. Energy Policy 48:64-75. https://doi.org/10.1016/j.enpol.2012.04.042

Schreiber M (2021) Governance of energy innovations. In: Hettich P, Kachi A (eds) Swiss energy governance. Springer, New York, pp 175-194

Singh HV, Bocca R, Gomez P, Dahlke S, Bazilian M (2019) The energy transitions index: an analytic framework for understanding the evolving global energy system. Energy Strategy Rev 26:100382. https://doi.org/10.1016/j.esr.2019.100382

Sioshansi F (2018) Three new energy companies finding value in three new business models, energypost.eu, 31 May 2018. Available at https://energypost.eu

Smil V (2010) Energy transitions: history, requirements, prospects. Praeger Publishers Inc, Santa Barbara, Calif

Swiss Federal Office for the Environment (2019) Economy and Consumption: In Brief. Available at https://www.bafu.admin.ch

Swiss Federal Office of Energy (2019) Energy in buildings. Available at https://www.bfe.admin.ch

WEF (2018) Fostering effective energy transition - a fact-based framework to support decisionmaking. World Economic Forum, Geneva

WEF (2019a) Fostering Effective Energy Transition 2019. Available at https://reports.weforum.org

WEF (2019b) Cyber resilience in the electricity ecosystem: principles and guidance for boards. World Economic Forum, Geneva. Available at https://www.weforum.org

WEF (2019c) The speed of the energy transition - gradual or rapid change, white paper, September 2019. World Economic Forum, Geneva. Available at https://www.weforum.org

Wehrmann B, Wettengel J (2019) Polls reveal citizens' support for Energiewende. Clean Energy Wire, 21 October 2019. Available at https://www.cleanenergywire.org

Wells P (2015) New business models and the automotive industry. In: Nieuwenhuis P, Wells P (eds) The global automotive industry. John Wiley \& Sons, Boston, pp 209-217. https://doi.org/ 10.1002/9781118802366.ch18

Würtenberger L, Bleyl J (2012) Business models for renewable energy in the built environment. Energy Research Centre of the Netherlands. Available at http://iea-retd.org 
Mary Jean Bürer is a senior researcher at the Haute école d'ingénierie et de gestion du canton de Vaud, HES SO at Yverdon-les-Bains, Switzerland.

Matthieu de Lapparent is a professor at the Haute école d'ingénierie et de gestion du canton de Vaud, HES SO at Yverdon-les-Bains, Switzerland.

Massimiliano Capezzali is a professor at the Haute école d'ingénierie et de gestion du canton de Vaud, HES SO at Yverdon-les-Bains, Switzerland.

Mauro Carpita is a professor at the Haute école d'ingénierie et de gestion du canton de Vaud, HES SO at Yverdon-les-Bains, Switzerland.

Open Access This chapter is licensed under the terms of the Creative Commons Attribution 4.0 International License (http://creativecommons.org/licenses/by/4.0/), which permits use, sharing, adaptation, distribution and reproduction in any medium or format, as long as you give appropriate credit to the original author(s) and the source, provide a link to the Creative Commons license and indicate if changes were made.

The images or other third party material in this chapter are included in the chapter's Creative Commons license, unless indicated otherwise in a credit line to the material. If material is not included in the chapter's Creative Commons license and your intended use is not permitted by statutory regulation or exceeds the permitted use, you will need to obtain permission directly from the copyright holder. 